\title{
Akzent auf die Standardsprachen: Regionale Spuren in "Français fédéral" und "Schweizerhochdeutsch""
}

\author{
Marie-José Kolly (Zürich)
}

\begin{abstract}
Durch ihren fremdsprachlichen Akzent gibt eine Sprecherin ihre Herkunft, ihre Muttersprache preis. So werden die meisten Deutschschweizer beim Sprechen einer Fremdsprache als solche erkannt. Kann aber aufgrund dieses "Deutschschweizer" Akzents auch erkannt werden, aus welchem Dialektgebiet ein Sprecher stammt? Der vorliegende Beitrag stellt eine empirische Studie zur Perzeption dialektaler Akzente vor. Er beschäftigt sich mit dialektalen Akzenten im Standarddeutschen und im Französischen und zeigt mit quantitativen Methoden auf, dass dialektal bedingte Akzentunterschiede von native speakers durchaus wahrgenommen und lokalisiert werden können. Darüber hinaus und als Basis für die Auswertung des empirischen Teils leistet die vorliegende Arbeit eine Beschreibung und Kategorisierung der dialektalen Lautlandschaft der Schweiz sowie einen Ansatz zur Beschreibung der Aussprache des Französischen durch Schweizer Dialektsprecher.
\end{abstract}

\begin{abstract}
Ich muss immer wieder die Sprache, die ich rede, verlassen, um eine Sprache zu finden, die ich nicht reden kann, denn wenn ich Deutsch rede, rede ich es mit einem berndeutschen Akzent, so wie ein Wiener Deutsch mit einem wienerischen Akzent spricht oder ein Münchner mit einem bayrischen Akzent. Ich rede langsam. Ich bin auf dem Land aufgewachsen, und die Bauern reden auch langsam. Mein Akzent stört mich nicht. Ich bin in guter Gesellschaft.
\end{abstract}

Dürrenmatt (1967/1998: 123)

\section{$1 \quad$ Einleitung}

"Klingt alles ziemlich nach: français fédérale [sic]"1. Diese spontane Äusserung eines Probanden erfolgte beim Anhören von Aufnahmen, auf welchen Schweizer Dialektsprecher ${ }^{2}$ Französisch sprechen. Zum einen wird damit ausgedrückt, dass die meisten Sprachproben einen Deutschschweizer Akzent $^{3}$ durchscheinen lassen; zum anderen lässt die Relativierung

\footnotetext{
* Eine Kurzversion dieses Artikels ist in expositionen 3/2011 erschienen.

1 Teilnehmer am Perzeptionsexperiment der vorliegenden Studie: Spontane Notiz auf Fragebogen. Français fédéral bezeichnet im Alltagsgebrauch ein von Deutschschweizern gesprochenes, fehlerbehaftetes und/oder akzentbeladenes Französisch (vgl. 3.2.2.2).

2 Im Folgenden werden weibliche und männliche Formen abwechselnd verwendet; mit der Nennung der einen Form ist in den meisten Fällen auch die andere mitgemeint.

${ }^{3}$ Im Gegensatz zum Wort- oder Satzakzent, die auf eine stärkere Betonung bestimmter Silben referieren, wird in dieser Studie Akzent definiert als "[t]he cumulative auditory effect of those features of pronunciation which identify where a person is from, regionally, or socially" (Crystal 2003: 3).
} 
der Aussage durch ziemlich vermuten, dass es dabei Abstufungen gibt - sowohl in der Intensität, als auch in der Qualität dieser Akzente.

Können Hörer die nationale, regionale oder sogar lokale Herkunft - also die Muttersprache (L1) - einer Person anhand ihrer Aussprache erkennen? Sprachen und insbesondere Zweitsowie Fremdspracherwerb ${ }^{4}$ sind Elemente unserer Diskussion sowohl auf politischer und wirtschaftlicher Ebene, als auch Thema am Kaffee-, Familien- oder Stammtisch. Es kann also davon ausgegangen werden, dass Schweizer Hörer eine für sprachliche Eigenheiten geschärfte Wahrnehmung haben. Wer mit offenen Ohren durch die Schweiz läuft, begegnet einer Vielzahl von verschiedenen fremdsprachlichen Akzenten: Zum Beispiel hört sich das Deutsch eines italienischsprachigen Tessiners ganz anders an als das eines Romands. Tönt auch das Standarddeutsch einer Berner Dialektsprecherin anders als das einer St. Gallerin? Bestimmen also die vielen unterschiedlichen Deutschschweizer Dialekte, die L1 der Mehrheit der Schweizer, ihren Akzent in der Schweizer Standardvarietät des Deutschen, dem Schweizerhochdeutschen, mit (zu dieser Hypothese vgl. Hove 2008: 70)? Für die meisten Dialektsprecher ist das Standarddeutsche nicht gerade eine Fremdsprache, aber doch eine Art Zweitsprache, eine "erweiterte" 5 Form ihrer L1. Wie steht es mit der Aussprache der ersten Fremdsprache (L2), welche die meisten Deutschschweizer lernen, des Französischen? Tönt das Français fédéral eines Westschweizer Dialektsprechers anders als das eines Ostschweizers? Ausgehend von solchen Fragestellungen soll im Rahmen der vorliegenden Untersuchung folgende Hypothese empirisch überprüft werden:

HYPOTHESE: Wenn ein Deutschschweizer Standarddeutsch oder Französisch spricht, kann ein native speaker eines Schweizer Dialekts erkennen, aus welcher Dialektregion der Sprecher stammt. Insbesondere können Stadtberner und Stadt-St.-Galler aufgrund ihrer standarddeutschen und französischen Äusserungen perzeptiv lokalisiert werden.

Diese Hypothese wurde experimentell getestet. Dafür wurden Perzeptionsexperimente mit dialektal gefärbten standarddeutschen und französischen Stimuli konstruiert. Als Stimuli dienten Aufnahmen von Sprechern aus zwei verschiedenen Schweizer Dialektgebieten: Stadtbernern und Stadt-St.-Gallern. Diese Aufnahmen enthielten sowohl Spontan- als auch Lesesprache, jeweils auf Standarddeutsch und Französisch. Sowohl deutsch- als auch französischsprachige Probanden beurteilten die Stimuli nach Akzentstärke und dialektaler Herkunft. Die Daten zur Akzenterkennung werden im vorliegenden Artikel vorgestellt; die Daten zur Akzentstärke und deren Zusammenhang mit affektiven Variablen werden in Kolly (2011) präsentiert.

Die Wahl zweier Dialekte aus dem Schweizer Mittelland resultiert aus dem Versuch, einen West/Ost-Kontrast zu erfassen. Die Beschränkung auf zwei Dialekte ist darin begründet, dass die Aufmerksamkeit der Hörer beim Perzeptionsexperiment durch die relativ langen Sprachproben jedes Sprechers in zwei Sprachen und zwei Sprechstilen schon stark strapaziert wird. Der Einbezug einer gewissen sprechstil- und sprecherbezogenen Variabilität zum Zweck der Robustheit der Resultate wurde hier dem Einbezug von weiteren Dialektgebieten vorgezogen. Guntern (2011) präsentiert demgegenüber ein Experiment zur Erkennung von acht dialektalen Akzenten im Standarddeutschen (je ein Sprecher).

Die theoretische Grundlage, welche für die vorliegende empirische Studie einen Rahmen bildet, hebt zum einen die relevanten Aspekte der Forschung zu fremdsprachlichen Akzenten hervor. Insbesondere geht es dabei sowohl um Sprachproduktion, als auch um

\footnotetext{
${ }^{4}$ Von Zweitspracherwerb wird meist dann gesprochen, wenn die Sprache in einem Kontext erworben wird, wo sie in der Umgebung der Lerner alltäglich vorkommt (vgl. Häcki Buhofer/Burger 1998: 14).

5 Terminus in diesem Zusammenhang von Häcki Buhofer/Burger (1998: 137): "Der Typ von Spracherwerb [...] lässt sich am besten als erweiterter Erstspracherwerb mit einigen Zügen von Zweitspracherwerb charakterisieren"; im Folgenden wird deshalb auch für das Standarddeutsche die Abkürzung "L2" verwendet.
} 
Sprachperzeption. Zum anderen werden die Sprachen (L2), Dialekte (L1) und die daraus resultierenden Akzente, die für die vorliegende Untersuchung eine Rolle spielen, in einem für die Schweiz relevanten Kontext diskutiert. Besonders wichtig ist dabei, da im Experiment die Frage nach dem dialektalen Akzent offen gestellt wurde, eine dialektologisch fundierte Kategorisierung der sehr breit gestreuten Antworten der Hörerinnen. Dafür muss die dialektale Lautlandschaft der Schweiz näher betrachtet und diskutiert werden.

\section{$2 \quad$ Fremdsprachlicher Akzent}

Der theoretische Rahmen zum fremdsprachlichen Akzent stellt verschiedene Studien zur Akzentperzeption und -produktion in ihrer Bedeutsamkeit für die vorliegende Untersuchung dar. Das erste Unterkapitel betrachtet die perzeptive Erkennbarkeit unterschiedlicher Akzente und Varietäten, das zweite Unterkapitel legt dar, an welchen lautlichen Phänomenen sich der globale Hörereindruck eines fremdsprachlichen Akzents festmachen lässt.

\section{1 "Fremde" Sprachen und Varietäten wahrnehmen}

Wie genau verschiedene Varietäten einer Sprache, insbesondere auch verschiedene Akzente, von einer Hörerin kognitiv wahrgenommen und kategorisiert werden, ist noch weitgehend unerforscht. Berthele (2010: 259) erwähnt potentielle kategorienbildende Faktoren wie "Intonations- und Lautbilder [...], instantiiert über memorisierte Wendungen, Wörter und Sätze", aber auch die Bedeutsamkeit prototypischer Sprecher als Repräsentanten einer Varietät. Der Zusammenhang zwischen einem Lautbild und der Visualisierung desselben wird bei Berthele (ebd.: 254-262) empirisch belegt: Seine Probanden ordnen dem Zürcher und dem St. Galler Dialekt eher spitze, scharfe Formen zu, Bern-, Basler- und Walliserdeutsch werden eher als runde Varietäten wahrgenommen. Dies hängt wahrscheinlich mit den Vokalsystemen der jeweiligen Dialekte zusammen. So resultiert aus einem Kunstwortexperiment, dass optisch runde Formen mit offenen Vokalen und optisch spitze Formen mit geschlossenen Vokalen in Verbindung gebracht werden (vgl. ebd.: 262). Interessant ist dabei auch das implizite Bewusstsein der Sprecherinnen für lautliche Dialektunterschiede: Berthele (ebd.: 261) beschreibt eine Situation mit einer Bernerin, die einen St. Galler Dialekt zu imitieren versucht und dabei die Grundfrequenz ihrer Stimme stark hebt. Dies erklärt die Probandin damit, dass die St. Galler beim Sprechen die Zunge anheben - womit sie die Tatsache beschreibt, dass das St. Galler Vokalsystem geschlossenere, höhere (Zungenhöhe) Laute enthält als Westschweizer und insbesondere Berner Vokalsysteme (vgl. 3.1.2). Schweizer Dialektsprecherinnen verfügen also über gewisse mentale Repräsentationen, was lautliche Charakteristika ihrer Nachbardialekte angeht.

Solche mentale Repräsentationen erlauben es Hörern, verschiedene Varietäten wieder zu erkennen, zu lokalisieren. Leemann/Siebenhaar (2008) weisen dies für prosodische Merkmale nach: Mit Hilfe eines Tiefpassfilters delexikalisieren sie Tonaufnahmen von "prototypischen" Schweizer Dialektsprechern aus Bern, Zürich, dem Wallis und dem Graubünden; segmentale Informationen sind dabei nicht mehr erkennbar. In einem Perzeptionsexperiment mit Berner und Zürcher Hörern konnten die Sprachproben der Berner, Zürcher und Walliser Sprecher rein aufgrund prosodischer Merkmale identifiziert werden (vgl. ebd.: 525f.). Guntern (2011) untersucht die Erkennbarkeit von dialektalen Akzenten bzw. Dialekten anhand von standarddeutschen bzw. dialektalen Stimuli. Ihre Probanden erkennen dialektale Akzente aufgrund von acht standarddeutschen Stimuli mit Sprechern aus den Kantonen Basel, Bern, Freiburg, Graubünden, St. Gallen, Schwyz, Wallis und Zürich durchschnittlich mit einer Rate von 53\%, wobei der Berner und der St. Galler Sprecher sogar mit einer Rate von 76\% bzw. $73 \%$ erkannt wurden. Bern- und St. Gallerdeutsch scheinen also in den mentalen Repräsentationen der Deutschschweizer besonders hervortretend zu sein. Die Frage nach der dialektalen Herkunft der Sprecher wurde bei diesen beiden Experimenten nicht frei gestellt, sondern führte die in den Aufnahmen enthaltenen Dialekte bzw. Akzente als multiple-choice- 
Antworten auf; so gehen auch viele andere Perzeptionsstudien vor (vgl. z. B.; Boula de Mareuïl u. a. 2008: 140; Purschke 2010: 157). Eine differenziertere Fragestellung verwendet Bauvois (1996: 297), die ihre belgischen Sprecher durch belgische Hörer sowohl frei regional (nach Himmelsrichtungen) als auch anhand einer multiple-choice-Struktur nach Städten verorten lässt. Auch Cunningham-Andersson/Engstrand (1989: 56) stellen ihre Frage in einem ersten Teil halboffen, indem ihre schwedischen Probanden angeben sollen, ob sie in der vorgespielten Aufnahme einen fremdsprachlichen Akzent, einen regionalen schwedischen Akzent oder lediglich eine merkwürdige Aussprache hören; zusätzlich können sie gegebenenfalls frei angeben, welchen speziellen fremdsprachlichen Akzent sie zu erkennen glauben. In einem zweiten Teil werden multiple choice Antworten vorgegeben (vgl. ebd.: 58). Bauvois' (1996: 301-303) Untersuchung zielt auf die Identifizierbarkeit regionaler Akzente ab. Ihre Sprecher aus fünf verschiedenen Städten wurden regional durchschnittlich von 36\% der Probandinnen erkannt; auf die multiple-choice-Frage nach der Herkunftsstadt erfolgten im Schnitt etwa 14\% korrekte Antworten. Boula de Mareuill u. a. (2008) untersuchen in ihrem Perzeptionsexperiment die Erkennbarkeit eines deutschen, englischen, arabischen, spanischen, italienischen und portugiesischen Akzents im Französischen. Alle Akzentgruppen wurden mit einer Identifikationsrate von über 50\% erkannt (vgl. ebd.: 158f.).

Native speakers (NaS) können sehr subtile Spuren eines fremdsprachlichen Akzents wahrnehmen, dies auch für sehr kurze Sprachproben (vgl. Thompson 1991: 178) - über die akustischen Merkmale, welche diese Wahrnehmung primär bewirken, ist man sich aber noch uneinig. Boula de Mareuil u. a. (2008: 143) geben aufgrund vergleichender akustischer Messungen und der Kommentare ihrer Probanden an, "que l'information portée par les segments (l'articulation des phonèmes) permette d'identifier l'origine d'un accent en français mieux que la prosodie, qui ne fait pas ressortir des tendances bien tranchées" (ebd.: 158). Dem widersprechen zahlreiche Publikationen, welche für die Akzentwahrnehmung die grundlegende Rolle prosodischer Faktoren betonen (vgl. 2.2). CunninghamAndersson/Engstrand (1989) weisen experimentell nach, dass ganz bestimmte Mengen und Kombinationen von abweichenden, segmentalen und prosodischen Merkmalen im Schwedischen den Höreindruck eines Finnischen Akzents bewirken. Je mehr solche Merkmale in einer Sprachprobe vorkommen, desto häufiger wird sie als "fremdsprachlich" eingestuft und als desto stärker wird der Akzent wahrgenommen. Ebenso gibt es Merkmale, die einzeln einen als stärker wahrgenommenen Akzent bewirken als die Kombination mehrerer anderer Merkmale (vgl. ebd.: 56f.).

Oft erkennen Probanden Sprecher aus der eigenen Gruppe im Bezug auf Geschlecht, Alter oder regionale Herkunft besser als Sprecher aus anderen Gruppen (vgl. Bauvois 1996: 294, 301f.). Dieser Grundsatz wird durch die Daten von Leemann/Siebenhaar (2008: 526) relativiert: Einerseits wurde der Bündner Dialekt durch Zürcher Probanden besser erkannt als durch Berner und der Walliser Dialekt durch Berner besser erkannt als durch Zürcher, was wahrscheinlich auf Kontaktphänomene zwischen den jeweiligen Dialektgruppen zurückzuführen ist. Interessant ist aber, dass andererseits die Berner Sprecher von den Zürcher Probanden besser erkannt wurden als von den Bernern selbst, und umgekehrt: "[I]n one's own perception, the 'other' variety is normally more marked" (ebd.: 527).

\section{2 "Fremde" Sprache produzieren}

Eine Vielzahl von segmentalen, silbischen und prosodischen Aspekten der L2-Aussprache trägt zum globalen Hörereindruck eines fremdsprachlichen Akzents bei. Beim L2-Erwerb muss einerseits gelernt werden, neue Laute und Lautverbindungen zu artikulieren, also neue motorische Bewegungen anzuwenden und vor allem zu automatisieren. Andererseits gehören 
zum Erwerb aber auch prosodische Merkmale der $\mathrm{L}^{6}{ }^{6}$, das Wissen über distinktive Merkmale, Phone, Allophone und Silben, die Anwendung von Koartikulations- und Reduktionsphänomenen usw. (vgl. z. B. Major 2001: 12; Molnár 2010: 2).

Gemäss Flege (1992: 589) sind prosodische Fehler für einen fremdsprachlichen Akzent weniger bedeutsam als segmentale. Jedoch fügt er an, dass manche segmentale Fehler aus dem Einfluss von Suprasegmentalia, z. B. der rhythmischen Akkuratheit, auf die segmentale Ebene entstehen können (vgl. ebd.: 595). Demgegenüber sieht die neuere Forschung für die Akzentwahrnehmung in der Prosodie eine Schlüsselrolle (vgl. z. B. Jilka/Möhler 1998; Atterer/Ladd 2004; Hirschfeld/Trouvain 2007: 171). So zeigt z. B. eine empirische Untersuchung von Missaglia (2007: 249), dass NaS bei der Beurteilung von Akzentstärke stärker durch die suprasegmentale (46.6\%) als durch die segmentale Kompetenz $(22.5 \%)$ der Sprecher beeinflusst werden.

Bei der Produktion von L2-Lauten sind Interferenzen zu erwarten, da L2-Lerner - im Gegensatz zu Kindern beim Erstspracherwerb - schon über ein phonologisches Lautsystem und einen motorisch eingeübten Sprechapparat für die Produktion ihrer L1 verfügen. Lerner tendieren dazu, die für ihre L1 irrelevanten akustischen Unterschiede nicht wahrzunehmen, insbesondere wenn z. B. ihr eigenes Vokalsystem weniger Laute (d.h. weniger und somit grössere Kategorien) enthält als das Vokalsystem der zu erwerbenden Sprache. Ein falsch wahrgenommener L2-Laut kann, wenn der Lerner seine Lautproduktion auf auditivem L2Input aufbaut, selbstverständlich nicht authentisch ausgesprochen werden. Illustriert wird dies zusätzlich durch eine Studie von Catford/Pisoni (1970: 480f.), die nachweist, dass "exotische" Laute durch rein artikulatorisches Training und ohne je gehört worden zu sein besser gelernt werden, als durch die Imitation eines Vorsprechers auf auditiver Basis. Lautwahrnehmung erfolgt L1-spezifisch, also nach der Hierarchie von distinktiven Merkmalen, welche für die jeweilige L1 relevant ist. So werden etwa einzelne distinktive Merkmale wie Aspiration oder Vokallänge je nach L1 der Sprecherin unterschiedlich gewichtet: In manchen Sprachen wird z. B. der Kontrast /t/ vs. /d/ vorwiegend durch Stimmhaftigkeit unterschieden, in anderen durch Längenunterschiede oder Aspiration. Neben dieser L1-spezifischen Wahrnehmung scheint es auch universelle Strategien für das Erlernen von Lauten zu geben: So wurde z. B. beobachtet, dass sich Lernerinnen bei der Unterscheidung von L2-Vokalen eher auf quantitative als auf qualitative Aspekte stützen, auch wenn in ihrer L1 Vokalquantität nicht distinktiv ist. Typologisch unmarkierte Laute, die auch Kinder als Erste erwerben, sind die, welche in der L2-Aussprache mit den wenigsten phonetischen Abweichungen wiedergegeben werden (vgl. Flege 1992: 570-571, Leather/James 1996: 293-295). Die Hypothese, dass eine grobe, universelle Reihenfolge für das Erlernen von Phonemen existiert und dass die vereinfachenden phonologischen Prozesse, welche Kinder beim Erstspracherwerb anwenden, in allen Sprachen ähnlich sind, wird zwar vielenorts gestützt, muss jedoch mit einer gewissen Flexibilität gehandhabt werden. So zeigen z. B. Holm/Dodd (2006) und Fox (2006), dass Lauterwerb durchaus auch sprachspezifisch erfolgt. Beim Erwerb des Deutschen ersetzen z. B $40 \%$ der Kinder in einem ihrer Entwicklungsstadien [s] und [z] durch [ $\theta]$ und [ð]. Unter allen bisher beschriebenen Sprachen treten diese speziellen phonologischen Prozesse jedoch nur für das Deutsche und das Maltesische auf (vgl. 2006: 64f.).

Segmentale Fehler sind ohne Zweifel von hoher Relevanz für den Höreindruck eines fremdsprachlichen Akzents. Die noch in den 1950er und 1960er Jahren geltende Ansicht der Contrastive Analysis, dass die Güte der Produktion eines L2-Lautes linear von seiner

\footnotetext{
${ }^{6}$ Längenkontraste, Timing, Ton, Intonation, Rhythmus, lexikalischer sowie Satzakzent (Akzent hier im Sinne von 'Betonung').
} 
perzipierten Distanz ${ }^{7}$ zum nahesten L1-Laut abhängt - dass also ein Laut authentischer produziert wird, wenn er eine nahe Entsprechung im L1-Lautsystem hat - muss revidiert werden. Folgende Kategorisierung beschreibt die Tatsachen realistischer (vgl. Flege 1992: 566, 572-577):

- Ein L2-Laut ist identisch zu einem L1-Laut $\Rightarrow$ der L2-Laut kann authentisch produziert werden ${ }^{8}$

- Ein L2-Laut verhält sich zum nahesten L1-Laut so ähnlich, dass eine Substitution des einen Lautes durch den anderen unerkannt bleibt $\Rightarrow$ der Laut wird als authentisch produziert wahrgenommen

- Ein L2-Laut weicht stark genug vom nahesten L1-Laut ab, dass er bei einer Substitution sofort als nicht authentisch erkannt wird, jedoch nicht genug, als dass er im Phonemsystem der Lernerin den Ansatz einer neuen Lautkategorie bewirkt $\Rightarrow$ die authentische Produktion des L2-Lautes ist erheblich erschwert und benötigt viel Übung $^{9}$

- Ein L2-Laut weicht von allen L1-Lauten erheblich $\mathrm{ab} \Rightarrow$ der Lerner bildet eine neue Lautkategorie und der Laut kann, nach genügend auditivem L2-Input und/oder artikulatorischem Training authentisch produziert werden

Neben den oben beschriebenen segmentalen Aspekten sind auch silbische Aspekte für fremdsprachliche Akzente relevant. Dazu gehören z. B. L2-Laute, die zwar im L1Phonemsystem eine Entsprechung haben, in der L2 jedoch in anderen phonotaktischen Kontexten auftreten (vgl. Flege 1992: 567-569). Die Silbenstruktur in der L2 wird von Lernern oft der eigenen L1-Silbenstruktur angepasst, so wie auch Lehnwörter silbisch oft der Zielsprache angepasst werden (vgl. Major 2001: 15). Weiter werden Laute je nach lautlicher Umgebung und Position im Wort von Lernenden unterschiedlich wahrgenommen, und auch mit unterschiedlicher Präzision wiedergegeben. So begünstigt z. B. der Wortanfang eine präzise Perzeption und Produktion: Viele Französischsprachige sprechen ein deutsches /a/ in ganz nasalisiert aus; sie kennen aber, auch in ihrer L1, sehr wohl ein nicht nasalisiertes /a/ vor /n/, z. B. in Anne. Hier ist von einem Einfluss sowohl der Umgebung und der Position im Wort als auch der Schrift auszugehen.

Weiter sehen wie oben beschrieben viele Forscher in der Prosodie den ausschlaggebenden Faktor für den Höreindruck eines fremdsprachlichen Akzents. Dies betrifft Abweichungen bei der Produktion von Wort- oder Satzakzent, Rhythmus, Ton und Intonation, Längenkontrasten und Timing. Einerseits irritiert es, wenn Wort- oder Satzakzent nicht oder falsch gesetzt werden, andererseits fällt aber auch eine abweichende phonetische Realisation derselben, z. B. durch die falsche Kombination der Faktoren Lautstärke, Tonhöhe und Länge, auf. Auch rhythmische Aspekte werden aus der L1 auf die L2 übertragen und sind ein starker Faktor für die Sprachwahrnehmung und -identifizierung. Typologisch werden dabei silbenzählende Sprachen von wort- oder akzentzählenden Sprachen unterschieden, wobei erstere

\footnotetext{
${ }^{7}$ Zur Messung dieser Distanz schlägt Flege (1992: 573) verschiedene Methoden vor, so z. B. das Ansetzen oder nicht eines anderen IPA-Symbols für den L2-Laut oder die auditive Wahrnehmbarkeit eines Unterschieds durch $\mathrm{NaS}$ und non native speakers ( $\mathrm{NNaS}$ ).

${ }^{8}$ Es kommt vor, dass manche L2-Laute identisch zu L1-Lauten sind. Meist unterscheiden sie sich aber, wenn auch nur minim, in ihrer Qualität, Quantität, Amplitude oder in den phonotaktischen Regeln, die sie betreffen (vgl. Flege 1992: 572).

${ }^{9}$ Ein typisches Beispiel dafür sind sprachspezifische voice-onset-time-Werte bei plosiven Konsonanten (vgl. Flege 1992: 578).
} 
phonologische Strukturen zur Optimierung der Silbe ${ }^{10}$ unterstützen, letztere solche zur Profilierung des Worts $^{11}$. Die neuere Forschung sieht dabei nicht mehr zwei streng distinkte Gruppen, sondern eher ein Kontinuum - auf welchem Sprachen wie (Standard-)Deutsch, Englisch, Russisch eher bei den Wortsprachen angesiedelt sind, Französisch und Spanisch eher bei den Silbensprachen (vgl. Auer 2001: 1391-1394). Dass die Übertragung rhythmischer Muster für den fremdsprachlichen Akzent ausschlaggebend ist, zeigt z. B. Missaglia (2007: 245) für italienischsprachige Lerner des Deutschen. Atterer/Ladd (2004) diskutieren einen Ansatz, der die Intonationskurven eines Sprechers in ein Verhältnis zu segmentalen Werten setzt: Der temporale Einsatz der Tonhöhenvariation bezüglich segmentaler Stützpunkte innerhalb einer Sprache (alignment) erfolgt nach einem bestimmten System, sieht aber von Sprache zu Sprache unterschiedlich aus. Diese einzelsprachlichen Muster werden durch Sprecherinnen auch in die L2 übertragen. So kann ein Unterschied zwischen nord- und süddeutschen Sprechern festgestellt werden, sowohl beim Sprechen ihrer L1-Varietät, als auch in ihren L2-Äusserungen (vgl. ebd.: 191-193). Abweichungen bei der Produktion von Längenkontrasten kann ebenfalls zum Akzent beitragen, auch wenn Quantität in der Zielsprache nicht distinktiv ist. Schliesslich beeinflussen auch Tempo und Pausensetzung den Akzent eines Sprechers (vgl. Strik/Cucchiarini/Binnenpoorte 2000).

\section{Sprachen in der Schweiz: Akzente soweit die Ohren reichen}

In der deutschsprachigen Schweiz werden vorwiegend Dialekte gesprochen und die deutsche Standardsprache geschrieben, ${ }^{12}$ Französisch wird meist als erste L2 in der Primarschule eingeführt. Im ersten Unterkapitel wird, vorausgreifend auf die Kategorisierung der breit gestreuten Antworten aus dem Perzeptionsexperiment, eine lautliche Beschreibung der Schweizer Dialektlandschaft versucht. Insbesondere wird dabei auf phonetische Kontraste zwischen Berndeutsch und St. Gallerdeutsch eingegangen, die sich als Schweizer Dialekte auch lautlich erheblich von der Standardsprache unterscheiden:

Früher antworteten meine Kinder Frisch auf Deutsch, sprach er mit ihnen, weil sie glaubten, Zürichdeutsch sei schon Deutsch, eine Pointe, die weder ein Deutscher noch ein Westschweizer versteht. (Dürrenmatt 1967/1998: 120)

Im zweiten Unterkapitel werden die beiden Zielsprachen Standarddeutsch und Französisch näher betrachtet. Dabei soll besonders auf die Aussprache der Deutschschweizer im Standarddeutschen und im Französischen eingegangen werden.

\section{1 "Schweizerdeutsch"?}

"Es gibt Deutschschweizer Dialekte, aber: Schweizerdeutsch n'existe pas. Schweizerdeutsch ist ein etablierter Sammelbegriff für die Dialekte, die in der Deutschschweiz gesprochen werden [...]" (Christen 2005: 21; Hervorh. im Orig.). Sie gehören alle zum alemannischen Dialektraum - einzig der südbairische Dialekt, der in Samnaun (GR) gesprochen wird, fällt aus der Reihe (vgl. ebd.: 22; Haas 2000: 59). Hotzenköcherle (1984: 25) definiert "Schweizerdeutsch" ausdrücklich nicht als eine innersprachliche Realität, sondern ganz pragmatisch als Sprachraum, dessen Grenzen politisch oder geographisch definiert sind. Die "Deckung zwischen 'Sprachgrenze' und Staatsgrenze" (ebd.: 21) ist vor allem in der

${ }^{10}$ Kein oder ein schwacher Wortakzent, kaum Reduktionen (Vollvokale auch in Nebensilben), typologisch unmarkierte Silben, Vermeiden eines Aufeinandertreffens von Vokalen durch Konsonantenepenthesen, Vereinfachte Silbifizierung durch Geminaten usw. (vgl. Auer 2001: 1395-1398).

${ }^{11}$ Markierung der Wortgrenze (z. B. Glottisschlag, Auslautverhärtung im Standarddeutschen), Reduktion oder Komprimierung unbetonter Silben (z. B. silbische Konsonanten oder Schwa im Standarddeutschen), distinktiver Wortakzent, Erlauben komplexer Silbenstrukturen wie Konsonantencluster und das Aufeinandertreffen von Vokalen usw. (vgl. Auer 2001: 1395-1398).

$12 \mathrm{Vgl}$. hierzu 3.2.1. 
kollektiven Wahrnehmung vorhanden, in der Realität gibt es kein Dialektmerkmal, das die gesamte Deutschschweiz umfasst, und dabei nicht über die Landesgrenzen hinaus ginge (vgl. Haas 2000: 59). Es decken sich aber einzelne sprachliche Phänomene, die vom "grösseren" deutschsprachigen Raum abweichen:

Ausbleiben der nhd. Diphthongierung, Monophthongierung, Dehnung; $k$-Verschiebung im Anlaut, in der Gemination, nach $r, l, n$; Fortleben der alten Konsonantenstufen Lenis/Fortis/Geminate; [...] ā-Vokalismus von 'gehen', 'stehen' (mhd. gān, stān); Häufigkeit der Diminutive auf -li; Einzelzüge wie die Genusunterscheidung bei 'zwei', 'drei' usw. (Hotzenköcherle 1984: 21)

Bachmann (1908: 71) erwähnt für die prosodische Ebene auch unterschiedliche Realisierungen der Akzentsetzung im Vergleich zum restlichen alemannischen Gebiet, geht aber nicht auf Details ein. Die Deutschschweizer Dialekte zeichnen sich in manchen Bereichen durch das Bewahren eines älteren Sprachstands aus (z. B. Fortleben der mhd. Monophthonge [i, y, u] in Wörtern wie [mi:s] 'mein', [ny:] 'neu', [hu:s] 'Haus'), in anderen Bereichen sind sie überaus "modern" (z. B. Durchführung der Lautverschiebung von [k] zu [x] auch in Lautumgebungen wie in [trr:Xə] 'trinken' in südlichen, sog. höchstalemannischen Gebieten) (vgl. Christen 2005: 22).

\subsubsection{Lautliche Kontraste in der Schweizer Dialektlandschaft}

Die einzelnen Dialekte voneinander abzugrenzen ist schwierig - welche Kriterien legitimieren das Ansetzen eines eigenständigen Dialekts im Tal nebenan, welche nicht? Im Alltag hat sich als gängigste Art der Kategorisierung eine Einordnung nach Kantonen eingebürgert, was eine grobe Bestimmung erlaubt (vgl. Christen 2010: 273-281). In der Tat gibt es eine Vielzahl an Isoglossen, die Kantonsgrenzen folgen - insbesondere dann, wenn die Kantonsgrenze mit einer geographischen oder konfessionellen Grenze zusammenfällt (vgl. Haas 2000: 60). Dass die Kantone als Bestimmungsgrössen jedoch im Allgemeinen ein Konstrukt bilden, das mit der Realität nicht genau übereinstimmt, lässt sich exemplarisch am Berndeutschen als "eine[r] der hartnäckigsten Verbindungen von Mundart- und Kantonsvorstellung" (Hotzenköcherle 1984: 193) demonstrieren, dessen nördlichere (Stadtberndeutsch, Seeländer oder Oberaargauer Dialekt) und südlichere (Oberlandberndeutsch, Haslitaler Dialekt) Varietäten sehr heterogene Merkmalsverteilungen aufweisen. ${ }^{13}$ Im Hinblick auf die Vielzahl der verschiedenen Antworten beim Perzeptionsexperiment (vgl. 4.5.2) soll hier eine Kategorisierung der Schweizer Dialekträume vor allem für lautliche Variablen versucht werden. Gleich vorab soll festgehalten werden, dass die Erhebungen für den Sprachatlas der deutschen Schweiz (SDS), auf welchen Hotzenköcherles Untersuchungen von 1961 und 1984 basieren, den dialektalen Sprachstand um etwa 1900 wiedergeben. Es ist also zu erwarten, dass manche der daraus erschlossenen Befunde heute nicht mehr uneingeschränkt gelten. Für einen systematischen Einbezug suprasegmentaler Kriterien fehlen leider extensive Untersuchungen. Im Folgenden werden prosodische Eigenschaften der besprochenen Varietäten nur da erwähnt, wo sie in der Literatur diskutiert werden und für die vorliegende Untersuchung relevant sind.

Schon Bachmann (1908: 74) bespricht eine Einteilung der Deutschschweizer Sprachlandschaft in sechs Hauptgebiete:

- Nordwesten: BA ${ }^{14}$, BE (Jura), SO (Norden) AG (Fricktal) (ebenso bei Hotzenköcherle 1984: 71)

\footnotetext{
13 Konkrete Beispiele zu den genannten Varietäten finden sich z. B. bei Haas (2000: 70f.).

14 Auf die Unterscheidung nach Halbkantonen wird hier verzichtet; kodifiziert werden die drei geteilten Kantone nach Hotzenköcherle (1984) wie folgt: AI, AR > AP; BS, BL > BA; OW, NW > UW.
} 
- Nordosten: ZH, SH, TG, SG, AP (gemäss Hotzenköcherle (1984: 91) zusätzlich das nördliche Randgebiet von GR, von ZH nur das nördliche Randgebiet)

- Mittelland: AG, SO, BE (Mittel- und Seeland), FR (Murten), LU (Gäu), ZG, SZ, GL

- Südwesten: FR (Jauntal und Sensebezirk), BE (Oberland), VS

- Südosten: SG (Oberland), GR

- Restgruppe: LU (Entlebuch), UW, UR

Bachmann nennt hier die Mittelland-Gruppe mit Vorbehalt, da sie allzu Verschiedenartiges zusammenfasst. Ebenso relativiert er die Zuteilung von $\mathrm{ZH}$ zu den nordöstlichen Dialekten: Der Dialekt von ZH weicht im Grossteil des Kantons von denselben ab, was z. B. auch in Hotzenköcherle (1962a: Karte 43) veranschaulicht wird. Grundsätzlich teilt Hotzenköcherle (1961: 210) schon in seinem Aufsatz von 1961 die Raumstruktur der Schweizer Dialekte in drei grosse Bereiche ein: Reliktstellung des Südens, bzw. höchstalemannische Reliktstaffelung; Gegensatz West/Ost; Einfluss romanischer Elemente ${ }^{15}$. Es scheint also, dass die Nord/Süd-Unterschiede eher eine graduelle Zuordnung zu höchstalemannischen Eigenschaften darstellt, der Westen und der Osten stärker voneinander abgrenzbar sind. Schon Hotzenköcherle (ebd.: 217f.) und Haas (2000: 61-66) vermuten, entgegen früheren dialektologischen Arbeiten wie der von Bachmann (1908: 73), dass die Nord/Süd-Gegensätze weit hinter den Ost/West-Unterschieden zurückliegen, so wie auch in der schweizerischen Volkskunde die West/Ost-Achse die einzige bedeutende Konstante ist, wobei diese regionale Kulturgrenze im Bezug auf regionale Bräuche erstaunlicherweise viel bedeutender zu sein scheint als die sprachlich bedingte zwischen Deutschschweiz und Romandie.

Nördliche vs. südliche Varietäten Es ist schwierig, einzelne Kantone bzw. Dialektgebiete den nördlichen oder südlichen Varietäten zuzuordnen, da Isoglossen zu verschiedenen Sprachbereichen und -variablen keine eindeutige Abgrenzung erlauben; vielmehr liegt gegen Süden hin eine sukzessive Übereinstimmung mit höchstalemannischen Kriterien vor. Hotzenköcherle (1984: 153-155) zeigt, dass es entgegen der Verwendung des Begriffs "Höchstalemannisch" in der älteren Forschung ein klar umgrenzbares höchstalemannisches Gebiet nicht gibt. Haas' (2000: 58f., 69) Darstellung ist etwas weniger differenziert, er setzt ein hochalemannisches Gebiet im Norden der Schweiz an, definiert als höchstalemannisch die Dialekte ohne Hiatusdiphthongierung (im Norden der Schweiz: schnyye > schneie 'schneien', bиие > boue 'bauen', nü̈̈ > nöi 'neu', vgl. Abbildung 1) ${ }^{16}$, wovon er noch die Walliser (VS) Dialekte als südlichstes Sprachgebiet absetzt. Auch bei Hotzenköcherle gelten als uneingeschränkt südliche Varietäten nur die Walliser Dialekte. Besonders exemplifiziert wird das am erhaltenen dreiförmigen Verbalplural (wier mache, ier machet, schi machunt im Gegensatz zu mier mache $(d)$, ier mached, syy mache $(d))^{17}$, dessen nördliche Grenze "repräsentativ [steht] für eine ganze Gruppe weiterer südlichster Relikte" (Hotzenköcherle 1961, 210; Hervorh. im Orig.), insbesondere natürlich auch lautlicher. Wie Haas nennt aber auch Hotzenköcherle (ebd.: 211) als weitere wichtige Nord/Süd-Isoglosse die Hiatusdiphthongierung. Lautliche Isoglossen, die jeweils global noch nördlicher verlaufen, bilden der Gegensatz zwischen verdumpftem und unverdumpftem /a/ (Norden: [o:bə], Süden: [a:bə] 'Abend'; vgl. Hotzenköcherle 1984: Karte 4), die /k/-Verschiebung zu [x] oder [h] im Wortinneren nach /n/, in Wörtern wie 'trinken' (Norden: [trı́kxə], Südwesten: [trı:xə]; vgl.

\footnotetext{
${ }^{15}$ Dieser dritte Bereich ist für die vorliegende Untersuchung nebensächlich und wird im Folgenden nicht weiter behandelt.

16 Verschriftlichung nach Haas (2000: 59).

17 Verschriftlichung nach Haas (2000: 59).
} 
ebd.: Karte 5) und die Aussprache von aobd. iu (Norden: Monophthong, etwa [ty:f], Süden: Diphthong wie in [ty:f] 'tief'; vgl. ebd.), wobei die Stadt Bern nur für die 'tief'- und die 'Abend'-Isoglossen zum südlicheren Gebiet zählt.

Viele Nord/Süd-Isoglossen verlaufen im Voralpengebiet und teilen die Schweizer Dialektlandschaft in alpine und mittelländische Dialekte (vgl. ebd.: 47-50; Haas 2000: 6163). Haas (ebd.) diskutiert vor allem zwei Isoglossen, welche die Deutschschweiz in ein nördliches und ein südliches Sprachgebiet teilen: Zum einen die oben erwähnte, im Süden ausgebliebene Hiatusdiphthongierung, zum anderen die südliche Aussprache eines Sprossvokals in der Endung - $r n$ als -[rə] etwa in gärn > gääre 'gern'. Dabei gehören zum Norden der Deutschschweiz die Kantone BA, SO, AG, LU, ZH, SH, TG sowie der nördliche Teil der Kantone FR, BE (insb. die Stadt Bern), ZG, SG (insb. die Stadt St. Gallen), AP, GR. Zum Süden gehören somit die Kantone VS, UR, SZ, GL sowie ein südlicher Teil der Kantone FR, BE, ZG, SG, AP und GR. UW kennt keine Hiatusdiphthongierung und spricht die Endung $-r n$ als solche aus, steht also laut Haas zwischendrin; bei Hotzenköcherle (1984: Karte 5) jedoch gehört UW für diese beiden Isoglossen zum südlichen Teil des Sprachgebiets. Die wichtigsten Isoglossen, die auch für die Kategorisierung der Dialektregionen im empirischen Teil dieser Arbeit wichtig sind, sind in Abbildung 1 in blauer Farbe dargestellt.

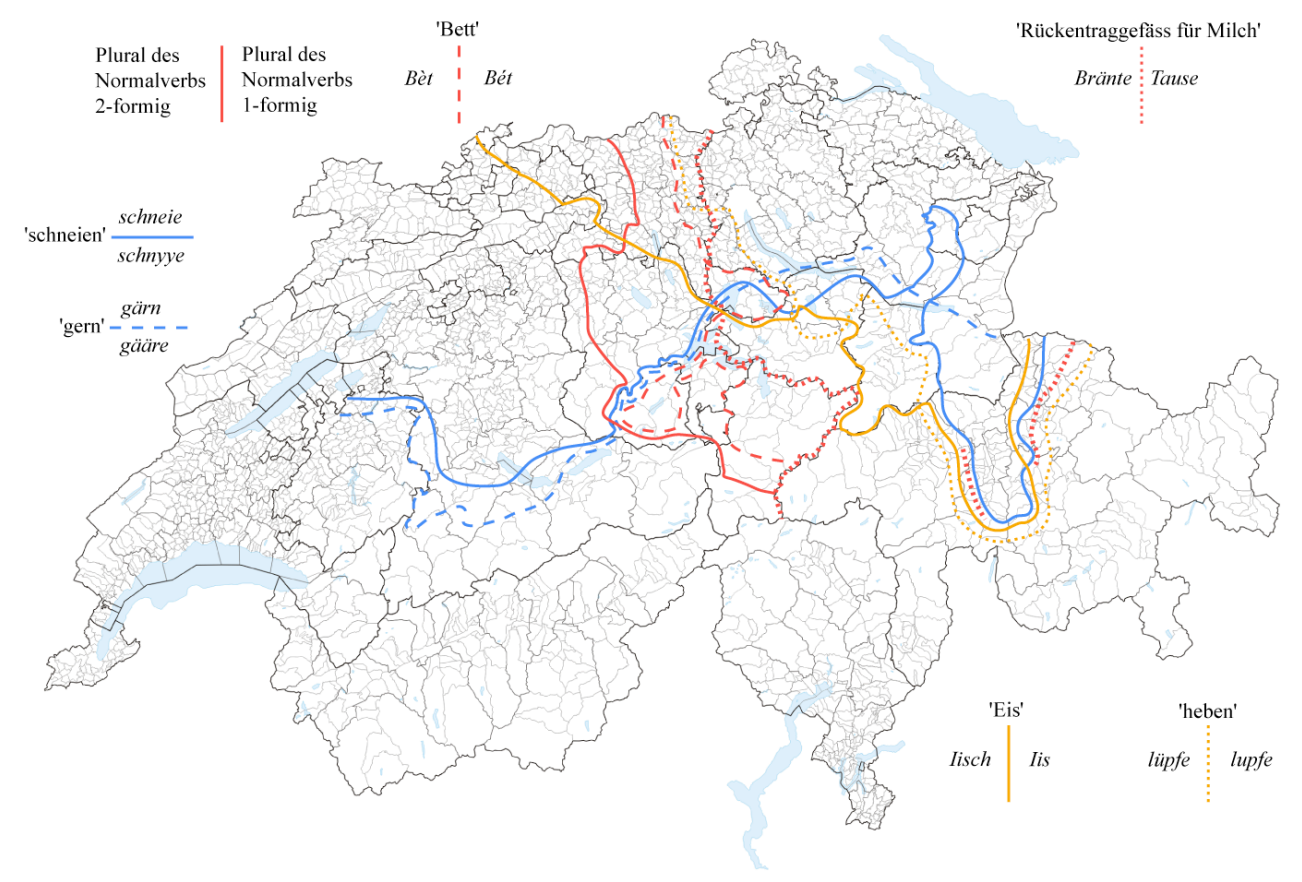

Abbildung 1: Isoglossen zur Einteilung der Schweizer Dialektgebiete in Nord/Süd- und West/OstKontraste (vgl. Haas 2000: 62, 65; Hotzenköcherle 1984: Karten 4f., 19-22)

Westliche vs. östliche Varietäten Grob gesagt liegt die dialektale West/Ost-Grenze, die insbesondere in grundverschiedenen phonetischen Inventaren und phonologischen Strukturen begründet wird, im Spannungsfeld zwischen Bern und Zürich (vgl. Hotzenköcherle 1961: 217, 1984: 69). Auch dieser Gegensatz ist aber effektiv ein Kontinuum, welches über die Kantone AG, LU, UW, UR, ZG, SZ, GL und sogar GR läuft (vgl. Hotzenköcherle 1961, Karte 18). Gemäss Haas (2000: 61) läuft ein Grossteil dieser Isoglossen durch die Kantone Aargau und Luzern. "Von paradigmatischer Bedeutung" (Hotzenköcherle 1961: 209) für die Raumstruktur der Schweizer Dialekte ist das oben im Bezug auf das VS im Süden erwähnte 
Kriterium der Verbalplurale. Im Westen, d. h. in den Kantonen FR, BE, SO, BA und in einem Teil der Kantone AG, LU, UW, UR und GR wurde der dreiförmige Verbalplural auf zwei Formen abgebaut, im restlichen, östlichen Gebiet - den Kantonen ZH, SH, TG, SG, AP, SZ, GL, ZG und einem Teil der Kantone AG, LU, UW, UR und GR - ist nur noch eine einzige, einheitliche Pluralform für Verben erhalten. Diese Isoglosse bildet "eine Art 'Rückgrat'" (Haas 2000: 64) für das Isoglossenbündel, das die Ost- von den Westschweizer Dialektmerkmalen unterscheidet. Als östliche Grenze der Grauzone in dieser West/Ost-Schattierung betrachtet Haas (ebd.: 65f.) die Isoglosse zwischen Bränte und Tause 'Rückentraggefäss für Milch'. Sie geht den Kantonsgrenzen entlang und ordnet FR, BE, VS, BA, SO, AG, LU, UW, UR dem westlichen Sprachraum zu, ZH, ZG, SZ, SH, TG, SG, AP, GL, GR dem östlichen. In der Grauzone liegen somit Teile der Kantone AG, LU, UW, UR, GR. Eine lautliche Isoglosse innerhalb dieses Graubereichs bildet z. B. die Lautung von /e/ in 'Bett': Im Westen des Sprachgebiets wird ein offenes $[\varepsilon]$ gesprochen, im Osten ein geschlossenes [e] (vgl. ebd.: 67; Hotzenköcherle 1962a: Karte 47). Damit gehören ZG und LU als ganze Kantone noch zum Westen, GR zum Osten, AG und UR sind gespalten und UW bildet ein Gebiet, wo beide Lautungen vorkommen: Eine Grauzone in der Grauzone. Interessant für die vorliegende Studie ist die Bemerkung bei Hotzenköcherle (1984: 51, Fussnote 2), dieser relativ schwache phonetische Unterschied werde in Grenzgebieten von Gewährsleuten spontan thematisiert; der Gegensatz ist also im mentalen Bewusstsein der Sprecher verankert. Die oben erwähnte globale Grauzone AG, LU, UW, UR, GR kann man mit Hotzenköcherle (1961: 218f., Karten 18f.; 1984: Karte 18) sowohl im Westen als auch im Osten noch etwas erweitern, die bei Haas definierte Schwingungszone scheint aber die Hauptlinie des West/Ost-Gegensatzes darzustellen. Insbesondere muss man den Raum ZH noch von der Ostschweiz abgrenzen (vgl. Hotzenköcherle 1961: 221-223, Karten 20-24; Bachmann 1908: 73).

Nun gibt es aber, wie bei Hotzenköcherle (1984: 52f., Karte 22) dargestellt, noch eine "abgedrehte" Variante der West/Ost-Kontraste, welche die Schweiz in einen (süd-)westlichen und einen nordöstlichen Bereich teilt. Lautliche Isoglossen, die diesen Befund illustrieren, bilden die Palatalisierung von /s/ in 'Eis' (Südwesten: [i:f], Nordosten: [i:s]) und die Umlautung in 'heben' (Südwesten: lüpfe, Nordosten: lupfe; Verschriftlichungen je nach Hotzenköcherle). Diese Isoglossen definieren einen südwestlichen Sprachbereich mit den Dialekten von FR, BE, SO, VS, UW, UR und einen nordöstlichen mit den Dialekten der Kantone ZH, SH, TG, SG, AP. Die relativ breite Grauzone umfasst BA, AG, LU, ZG, SZ, GL, GR. Abbildung 1 stellt auch die wichtigsten West/Ost- bzw. (Süd-)west/NordostIsoglossen auf der Karte dar, erstere in roter, letztere in gelber Farbe.

Grundsätzlich steht einem tendenziell eher einheitlichen westlichen Dialektgebiet ein aufgesplitterter Ostraum gegenüber (vgl. ebd.: 53, 61). Die "eigentliche" Ostschweiz (d.h. SH, TG, SG, AP, nördl. Randgebiete von ZH, GR) zeichnet sich durch eine sehr geschlossene Aussprache der Vokale aus, oft fehlt der für die Schweiz typische Laut [æ] und wird als $[\varepsilon]$ gesprochen, so z. B. in glèse 'gelesen' (vgl. Hotzenköcherle 1984: 91f.; Haas 2000: 72) ${ }^{18}$. Bei Haas (1985: 95-97, 106, Anmerkung 2) wird illustriert, wie die Anzahl an gesenkten mhd. Lauten (z. B. hunt $>$ [hond] ]) oder auch erhaltenen tiefen mhd. Lautqualitäten gegen Westen sukzessive zunimmt. Dabei bilden, hier etwas vereinfacht dargestellt, die Dialekte der Kantone SH, TG, SG, AP, GL den östlichsten Teil, in welchem keine Vokale gesenkt wurden. Es folgen GR, ZH, SZ, UR, UW mit einer einzigen Senkung; ZG, BA, SO und je ein Randteil der Kantone GR, AG, UW, UR, BE stellen die mittlere Entwicklung dar; AG, LU weisen mehr Senkungen auf und zählen hier zu den westlichen Gebieten; BE, ein Teil von FR und LU weisen die meisten Senkungen auf. Die Walliser Dialekte werden bei Haas (ebd.) der starken Variabilität wegen ausgeklammert, und auch Hotzenköcherle (1984: 51) lässt in seiner

18 Verschriftlichung nach Haas. 
Darstellung der West/Ost-Gegensätze die Sprachgebiete VS und GR meist weg, weil diese "ihre eigene Problematik" haben. Ein weiteres typisches Merkmal für die Unterscheidung West/Ost ist der /a/-Laut, der in der Ostschweiz sehr weit vorne im Vokaltrakt als [a], ab Zürich und weiter westlich als hinteres [a] oder [p] (gerundet) gesprochen wird (vgl. Siebenhaar 1994: 38; Fleischer/Schmid 2006). Auch wird in der Ostschweiz der /r/-Laut grösstenteils uvular (Vibrant: [R] oder Frikativ: [в]) oder als Approximant gesprochen, ab Zürich und im Westen meist alveolar (Vibrant: [r] oder Tap: [r]) (vgl. Werlen 1980). Schon Bachmann (1908: 73) bemerkt, dass im Osten generell "kräftiger und straffer" artikuliert wird, als im Westen. Dass zwischen den unterschiedlichen Schweizer Dialekten, insbesondere zwischen westlicheren und östlicheren, auch intonatorische und rhythmische Kontraste bestehen, wurde später von Leemann/Siebenhaar (2008), Leemann (2012), Leemann/Dellwo/Kolly/Schmid (2012) nachgewiesen. Alle aufgeführten (Laut-)Unterschiede grenzen insbesondere das westliche Gebiet BE vom östlichen SG ab.

Die Stellung der Zentralschweiz Die besondere Stellung der Zentralschweiz ${ }^{19}$ zwischen den Grossräumen BE und ZH, im Schnittfeld zwischen Nord/Süd- und West/Ost-Kontrasten, wird bei Hotzenköcherle (1984: 237-246) näher erläutert. Der Ansatz einer zusammenhängenden Sprachlandschaft ist berechtigt; im Ganzen stellt sie einen eher südlichen Sprachraum dar, wovon LU sowie der nördliche Teil von SZ und ZG häufig abzusetzen sind. Im West/OstGegensatz konstituiert die Zentralschweiz eine breite Grauzone: Mal gehört sie als Ganzes zum westlichen oder östlichen Teil der Schweiz, mal ist sie gespalten (vgl. ebd.: 237-245). Dabei kommt besonders dem alpinen Dialekt von UR eine Übergangsstellung von Südwesten nach Nordosten zu, dem von SZ eine von Norden nach Süden (vgl. ebd.: 268, 278). Die Sprachlandschaft von ZG ist ein "Tummelfeld" (ebd.: 287) von Varianten der benachbarten Sprachregionen zwischen Nord/Süd und West/Ost.

\subsubsection{Lautliche Kontraste zwischen Berndeutsch und St. Gallerdeutsch}

Das Berner und das St. Galler Vokalsystem unterscheiden sich sowohl in Bezug auf Zungenhöhe, als auch in Bezug auf Zungenlage. Dazu kommen die unterschiedliche Aussprache des /r/-Lautes im konsonantischen Bereich, sowie prosodische Unterschiede.

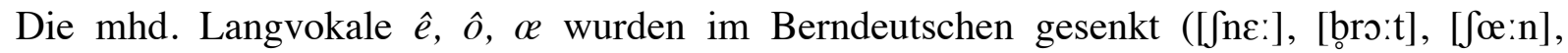
'Schnee', 'Brot', 'schön'). So enthält dieser Dialekt vermehrt offene Mittel- und Hochzungenvokale, im Gegensatz zum St. Gallerdeutschen, wo diese Laute überwiegend geschlossen gesprochen werden. In der Standardlautung kommen solche Vokale nur in geschlossener Form vor: [ [ne:], [bro:t], [〕ø:n] (vgl. Siebenhaar 1994: 37). In diesem Bereich werden also zumindest für die Berner Variante des Schweizerhochdeutschen Interferenzen erwartet. Auch fünf Kurzvokale wurden im Berndeutschen gesenkt,

wo etwa das Stadt-St.-Gallerdeutsche ungesenkte Vokale hat, und vier Langvokale sowie ein Kurzvokal wurden im St. Gallerdeutschen gehoben, während sie im Berndeutschen tief blieben. [...] Insgesamt haben wir also - rein statistisch gesehen - eine grosse Wahrscheinlichkeit, dass einem Tonvokal im Berndeutschen ein vergleichsweise höherer Laut im St. Gallerdeutschen entspricht. (Berthele 2010: 261)

Die beiden Dialekte unterscheiden sich auch in Bezug auf die Zungenlage bei der Artikulation von /a/: In Bern wird /a/ im Vokaltrakt hinten als [a] gesprochen, in St. Gallen weit vorn als [a].

19 Die Begriffe "Innerschweiz" und "Zentralschweiz" wurden hier und beim Auswerten der Daten zum Perzeptionsexperiment auf den Terminus "Zentralschweiz" vereinheitlicht. Zu dieser Region werden die Kantone UW, LU, SZ, UR und ZG gezählt (vgl. Historisches Lexikon der Schweiz s. v. "Innerschweiz": 640). 
Bei den Konsonanten muss die unterschiedliche Aussprache von /r/ erwähnt werden: Eine Bernerin spricht in der Regel einen alveolaren Vibranten [r], ein St. Galler einen uvularen Vibranten oder Frikativ ([ь] bzw. [R]), oder einen Approximanten [І] (sog. dorsale Artikulation, vgl. Werlen 1980), wobei hier auch Ausnahmen existieren. Ebenfalls vokalisieren Stadtberner /1/ zu [u] (selten auch velare Artikulation [1]), St. Galler sprechen einen Konsonanten [1] (vgl. Leemann u. a. 2012b, SDS 1962-2003: Bd. II, Karten 66, 149f., 197f.).

Auch auf der prosodischen Ebene sind Unterschiede zwischen Bern- und St. Gallerdeutsch zu erwarten, auch wenn empirische Untersuchungen $\mathrm{zu}$ prosodischen Aspekten des St. Gallerdeutschen allem Anschein nach noch ausstehen. Das Berndeutsche wird "überwölbt durch die Eigenart einer schwer $\mathrm{zu}$ beschreibenden, aber höchst ohrenfälligen, charakteristischen Intonation" (Hotzenköcherle 1984: 195), die auch bei Leemann/Siebenhaar (2008: 524) beschrieben wird: "The BE dialect distinguishes itself with [...] later pitch rises and later pitch falls, with regard to syllable starting point and syllable end point". Demgegenüber wird z. B. im Zürcher Dialekt im Bezug auf Stützpunkte in der Silbe der Pitch früher angehoben (alignment). Gemäss Atterer/Ladd (2004) werden solche Merkmale auch in eine L2 übertragen (vgl. 2.2). Zwischen nordöstlichen und südwestlichen Schweizer Dialekten bestehen auch rhythmische Unterschiede (vgl. Leemann/Dellwo/Kolly/Schmid 2012). Insbesondere unterscheiden sich Sprachproduktionen von Berner und Thurgauer Sprechern in Massen wie dem Prozentsatz an vokalischem Anteil und der zeitlichen Variabilität der vokalischen und konsonantischen Intervalle.

Das Wissen um solche lautliche Unterschiede innerhalb der deutschsprachigen Schweiz scheint auch im Sprachbewusstsein der bei Berthele (2010: 261) zitierten Sprecherin und seinen Probanden verankert zu sein, die eine relativ präzise Vorstellung davon haben, wie ein Ostschweizer Dialekt tönt (vgl. dazu auch 2.1.1). Auch die Grossräumigkeit der Berner Sprachlandschaft macht sie zu einem sehr prominenten, im Sprachbewusstsein der Deutschschweizer "tief verankerten" (Hotzenköcherle 1984: 195) Dialekt.

Wie bei Leemann/Siebenhaar (2008: 526) beschrieben, können Berner von Zürcher Sprechern rein aufgrund prosodischer Merkmale unterschieden werden. Basierend auf den vorangehenden Erläuterungen kann davon ausgegangen werden, dass die beschriebenen prosodischen Aspekte auch die auditive Unterscheidung von St. Galler und Berner Sprechern erlaubt. Solche segmentale und prosodische Unterschiede zwischen den Schweizer Dialekten führen vermutlich auch zu einem unterschiedlichen Akzent der Dialektsprecher in einer L2. Dies lässt insbesondere unterschiedliche Akzente im Schweizerhochdeutschen sowie im Französischen erwarten.

\subsection{Standarddeutsch und Französisch in der Deutschschweiz}

\subsubsection{Verteilung der beiden Standardsprachen}

Französisch wird in der deutschen Schweiz meist als erste L2 in der Schule gelernt, das Standarddeutsche in Form eines "erweiterte[n] Erstspracherwerb[s] mit Zügen von Zweitspracherwerb" (Häcki Buhofer/Burger 1998: 137). In einer Befragung von Werlen (2000: 272) geben Deutschschweizerinnen an, Französisch v. a. im französischsprachigen Sprachgebiet gelernt zu haben; als zweitwichtigste Quelle des Französischerwerbs wird die Schule angegeben.

Die Deutschschweiz zeichnet sich von anderen deutschsprachigen Regionen durch die Verwendung der Dialekte als Umgangssprache ab, unabhängig von Bevölkerungsschicht und Sprachsituation und somit ohne Stigmatisierung (Hotzenköcherle 1984: 25). So ist die Deutschschweiz eine der vier Regionen, anhand derer Ferguson (1959) das Phänomen der 
Diglossie beschreibt (vgl. Haas 2004: 81-83). Für die Deutschschweizer Sprachsituation hat Kolde (1981: 65-72) den Begriff der "medialen" Diglossie geprägt: Die Deutschschweizerin spricht im Allgemeinen Dialekt, schreibt und liest aber im Normalfall auf Standarddeutsch die beiden Funktionen der Varietäten lassen sich also mit Mündlichkeit und Schriftlichkeit beschreiben. So wird Standarddeutsch in der Schweizer Umgangssprache bezeichnenderweise auch "Schriftdeutsch" genannt - was zum Ausdruck bringt, wie unnatürlich das Standarddeutsch-Sprechen zwischen zwei Deutschschweizern ist (vgl. Siebenhaar 1994: 31). Dass es zwischen dieser Mundart-Mündlichkeit und Standardsprachen-Schriftlichkeit auch Überlappungen und Grauzonen gibt ist selbstverständlich. So wird in Deutschschweizer Schulen und Universitäten, an Vorträgen, öffentlichen Reden und in den Medien generell Standarddeutsch gesprochen; private SMS sowie E-Mails und sogar manche Werbetexte werden vermehrt im Dialekt verfasst und Mundartliteratur gehört seit langem zur literarischen Tradition der Schweiz.

\subsubsection{Dialektaler Akzent in Standarddeutsch und Französisch}

\subsubsection{Schweizerhochdeutsch}

Unter "Schweizerhochdeutsch" wird die deutsche Standardsprache, wie sie in der Schweiz "mit unverkennbar lokaler Prägung" (Christen 2005: 21) (aus)gesprochen wird, verstanden. Die phonetische Realisierung des Schweizerhochdeutschen bespricht z. B. Hove (2002) anhand einer empirischen Untersuchung; die Einflussrolle einzelner Dialekte wird aber nur am Rande behandelt. Siebenhaar (1994) untersucht die Berner, Zürcher und St. Galler Aussprache in einer Anzahl vorgelesener standarddeutscher Wörter. Seine Ergebnisse zeigen, dass die Schweizer Standardsprache regionale, durch die jeweiligen Dialekte bedingte Artikulationsunterschiede aufweist. In diesem Korpus war die Aussprache der Zürcher am standardnahesten (vgl. ebd.: 65).

Die wichtigsten lautlichen Merkmale des Schweizerhochdeutschen, grösstenteils nach Hove (2002: 134f., 177) und Siebenhaar (1994: 41f.), sind folgende:

- Diphthonge und Qualität von /a/ oft mit dialektalen Interferenzen

- Vokale oft gesenkt

- hohes [e] tendenziell gesenkt als $[\varepsilon]$

- <-e in Nebensilben tendenziell mit [ع] statt Schwa [ə] (keine Vokalreduktion)

- palatales /j/ als vokalisches [i_]

- "ich-Laut" [ç] meist standardnah, also palatal realisiert; teilweise velar als [x]

- "ach-Laut" [x] oft überkorrekt zu weit vorne (palatal) realisiert; teilweise uvular als $[\chi]$

- /r/-Laut meist alveolar, als Vibrant oder als Tap, teilweise auch uvular

- vokalisierter/r/-Laut zu Schwa [e] selten, teilweise aber sogar übergeneralisiert

- intervokalische Konsonanten nach Kurzvokal oft geminiert

- Nebensilbe <-ig>als [ik] statt [iç]

- vereinzelte Realisierungen von $/ \mathrm{k} / \mathrm{als}[\mathrm{kx}]$

- stimmhafte Plosive [b, d, g, z] entsonorisiert als stimmlose Lenes

- Ausbleiben der Auslautverhärtung - auch hier werden Lenes realisiert

- Ausbleiben der Aspiration stimmloser Plosive, oder schwächere Aspiration

- Ausbleiben des Glottisschlags vor Vokal am Wortanfang

- silbische Konsonanten in unbetonten Nebensilben nur selten 
Auf der suprasegmentalen Ebene entsteht u. a. durch fehlende Vokalreduktionen ein etwas silbenzählenderer Rhythmus. Generell zum Sprachrhythmus muss bemerkt werden, dass das Standarddeutsche auf dem Kontinuum zwischen Wort- und Silbensprachen näher bei den Wortsprachen anzusiedeln ist, als die Schweizer Dialekte: In den Dialekten werden Vollvokale in Nebensilben nicht oder nur zum Teil reduziert, ein Glottisschlag wird nicht gesprochen, die Auslautverhärtung bleibt aus und Konsonantenepenthesen sowie Geminaten vereinfachen die Silbifizierung. Auch tendieren die Schweizer Dialekte eher zur Erstsilbenbetonung als die Standardsprache und manche Sprecher übertragen dies, wie auch andere rhythmische und prosodische Eigenschaften, auf ihre Aussprache des Standarddeutschen (vgl. Siebenhaar 1994: 37).

Bernerhochdeutsch Wie durch Dialektmerkmale zu erwarten ist (vgl. 3.1.2), senken Berner Dialektsprecherinnen die standarddeutschen geschlossenen Langvokale (vgl. Siebenhaar 1994: 37). Ebenfalls tendieren sie dazu, geschlossene Kurzvokale und das zweite Element von Diphthongen zu senken. Wie im Dialekt wird auch für die Aussprache des Standarddeutschen oft ein hinten im Vokaltrakt gesprochenes [a] verwendet. Stimmlose Plosive (Fortes) werden kaum aspiriert und die auslautenden Lenis-Konsonanten selten verhärtet. /1/ realisieren Berner selten auch velar als [ł]. Der/r/-Laut wird alveolar gesprochen. Der "ach-Laut" [x] wird häufig uvular als $[\chi]$ realisiert (vgl. ebd.: $54 f$.).

St. Gallerhochdeutsch Im Gegensatz zu den Bernern sprechen St. Galler die standarddeutschen Langvokale sowie Diphthonge im Allgemeinen standardnah aus, bei offenen Kurzvokalen tendieren sie sogar zu Hebungen (vgl. Siebenhaar 1994: 54). St. Gallerhochdeutsch ist oft durch ein vorne im Vokaltrakt gesprochenes [a] gekennzeichnet im Gegensatz zum standardsprachlichen [a] mit mittlerer Zungenlage (vgl. Hove 2002: 134). Stimmlose Plosive (Fortes) werden häufiger aspiriert als in Bern, besonders im Anlaut, und /d/ wird im Auslaut oft verhärtet. St. Gallerinnen verwenden eher silbische Konsonanten als Berner. Der/r/-Laut wird grundsätzlich uvular als [R], teilweise als Approximant [I] realisiert und auch eher zu Schwa [e] vokalisiert als in Bern. Teilweise unterlassen St. Galler Sprecher die Assimilation der Verbindung /nk/ (vgl. Siebenhaar 1994: 54f.).

\subsubsection{Français fédéral}

"Exgüsi silwouplä, mä schö parl pa trä pien frasä...tcho bone" ${ }^{20}$ - so und ähnlich wird das von Deutschschweizern gesprochene Französisch gerne parodiert. Der Helvetismus Français fédéral bezeichnet ein

Français germanisé (ou simplement fautif) des textes produits par l'administration centrale, ainsi que par les entreprises et agences de publicité dont le siège social est situé en Suisse alémanique; (par ext.) français germanisé (ou fautif) pratiqué par les Suisses alémaniques (et, éventuellement, par les Suisses romands). (Thibault 2004: 379)

Im Alltagsgebrauch wird der Begriff oft ausgedehnt und für ein schwer akzentbeladenes Französisch verwendet, das, so Lengert (1998: 260), ausserdem mit "lourd", "incorrect" und "maladroit" attribuiert wird. Das Zitat oben illustriert durch seine "lautnahe" Verschriftlichung ein paar Hauptaspekte des Deutschschweizer Akzents im Französischen: ${ }^{21}$ $<\mathrm{p}>$ in pien und $<\mathrm{sch}>$ in schö kennzeichnen die oft stimmlose Aussprache von [b, 3]; <a $>$ in fras ä das Ausbleiben der Nasalisierung; <ä> die überoffene Aussprache von $[\varepsilon]$ in -ais, -ait, -

\footnotetext{
${ }^{20}$ Kleideraufdruck, Design des Unternehmens Graphein in Fribourg; http://www.grapheinfactory.ch/index.php ?id=43.

21 Allem Anschein nach bildet die Aussprache des Französischen in der Deutschschweiz, bis auf die Untersuchung von Schmid (2009), eine Forschungslücke; Auf eine Darstellung der Literatur zur Aussprache des Französischen durch NaS des Standarddeutschen wird hier aufgrund der fraglichen Relevanz verzichtet.
} 
$\grave{e}$ - usw. Dieser prototypische Deutschschweizer Akzent kann auf folgende Charakteristika ausgedehnt werden:

- Diphthonge und Qualität von /a/ oft mit dialektalen Interferenzen

- zu offene, tiefe und weniger gespannte Artikulation der Vokale

- zu lange Vokale (im Französischen ist Quantität nicht distinktiv)

- Ausspracheprobleme bei nasalen Vokalen, ganz besonders für den Kontrast /ã/ vs. / $\tilde{\jmath} /$

- $\quad<$ r>-Laut vereinzelt alveolar

- stimmhafte Obstruenten [b, d, g, 3, z] entsonorisiert, teilweise und v. a. im Auslaut auch [v] (vgl. Schmid 2009)

- rhythmische Interferenzen aus dem Dialekt, der den Wortsprachen näher ist, als das Französische als Silbensprache

- zu viel Variation in der Intonation (das Französische hat einen monotoneren PitchVerlauf)

- zu starke Akzentsetzung, teilweise auf der falschen Silbe (das Französische hat einen schwachen Akzent jeweils auf der letzten Silbe eines Worts, der aber zugunsten einer Endbetonung in der Äusserungseinheit untergeht; vgl. Schmidt 2003: 4)

Auf dem Kontinuum zwischen Silben- und Wortsprachen dürfte das Französische als Silbensprache L1-Deutschen Sprecherinnen rhythmische Probleme bereiten. Da die Schweizer Dialekte aber auf diesem Kontinuum über weniger Merkmale der Wortsprachen verfügen als das Standarddeutsche, ${ }^{22}$ sind die rhythmischen Abweichungen von Deutschschweizer Sprechern im Französischen vermutlich weniger stark als die von Personen mit L1 Standarddeutsch (vgl. zur Diskussion der Unterscheidung von Silben- und Wortsprachen 2.2 sowie Auer 2001).

Die erwartbaren Unterschiede zwischen dem Berner und dem St. Galler Akzent betreffen v. a. Vokalqualität: Von den St. Galler Sprechern wird aufgrund ihrer L1-Phonologie eher ein vorderes [a] und geschlossene Vokale erwartet, von den Bernern ein hinteres [a] und offenere Vokale. Insofern beschreibt das Zitat oben eher die prototypische Aussprache eines Berners als die eines Ostschweizers. Bei St. Galler Sprechern wird nicht mit alveolaren /r/-Lauten gerechnet, wohl aber vereinzelt bei Bernern. Nasalvokale dürften allen Schweizer Dialektsprechern Mühe bereiten, ebenso Vokaldauern, stimmhafte Plosive sowie prosodische Eigenschaften des Französischen.

\section{Untersuchungsdesign und methodische Erläuterungen}

Sprecherinnen unterschiedlicher Schweizer Dialekte lassen sich auf auditiver Basis meist regional verorten. Dies geschieht gewöhnlich aufgrund der lautlichen Aspekte ihrer Äusserungen, da die charakteristischen lexikalischen Besonderheiten eines Dialekts beim Gespräch mit Sprechern aus anderen Regionen oft vermieden werden - im Bemühen um überregionale Verständlichkeit (vgl. Christen 2005: 23f.). Leemann/Siebenhaar (2008) weisen nach, dass Schweizer Dialektsprecher sogar aufgrund rein prosodischer Merkmale identifiziert werden können. Ob diese lautlichen und prosodischen Aspekte auch auf das Standarddeutsche und das Französische übertragen werden und eine Verortung der Sprecher aufgrund ihres dialektalen Akzents erlauben, wurde mit einem Perzeptionsexperiment geprüft. Dabei hörten Deutschschweizer und Romands französische und standarddeutsche Aufnahmen von je vier Deutschschweizern aus Bern und aus St. Gallen. Zu jedem Stimulus gaben sie frei an, aus welchem Dialektgebiet der jeweilige Sprecher stammen könnte.

${ }^{22} \mathrm{Vgl}$. dazu 4.2.2.1. 


\subsection{Probanden}

Primär sollte untersucht werden, ob Schweizer Dialektsprecher die beschriebenen dialektalen Akzente identifizieren können. Da diese dialektalen Akzente sowohl in standarddeutschen, als auch in französischsprachigen Stimuli präsentiert wurden, wurden für letztere auch frankophone Probanden getestet. Insgesamt nahmen 80 Probanden am Experiment teil:

- 60 deutschsprachige Probanden

- 14 Studierende der Universität Zürich

- 46 Studierende der Universität Bern

- 20 französischsprachige Studierende der Haute École de Gestion (HEG) Fribourg

Das Alter der Probanden (19-32) entsprach dem der Sprecherinnen, was die regionale Identifizierung letzterer potentiell begünstigen könnte: Gemäss Bauvois (1996: 305) werden Sprecher von Probanden aus ihrer Altersgruppe besser erkannt, als von viel älteren oder jüngeren Sprechern. Die frankophonen Probanden gaben als L1 durchgehend Französisch an, zwei Personen nennen zusätzlich suisse-allemand, eine Albanisch. Von den deutschsprachigen Probanden wurde als L1 mehrheitlich Berndeutsch genannt, weiter waren Zürichdeutsch-Sprecher dabei, "Ostschweizerdeutsch"-Sprecher, St. Galler, Thurgauer und Probanden mit Mischdialekten. An den Universitäten Bern und Zürich wurde das Experiment jeweils in germanistischen Veranstaltungen durchgeführt, an der HEG Fribourg in einer Deutschlektion.

\subsection{Stimuli}

\subsubsection{Sprecher}

Der Homogenität des Korpus halber wurden Sprecher und Sprecherinnen gewählt, die zum Zeitpunkt der Untersuchung alle zwischen 20 und 30 Jahre alt waren. Ausserdem wurden ausschliesslich Studierende aufgenommen, pro Dialektgebiet zwei Frauen und zwei Männer. So wurden also insgesamt acht Sprecher aufgenommen - zwar ist die Fragestellung phonetisch-phonologischen Charakters, was für die L1 wenig Variation im Bezug auf Geschlecht und Alter erwarten lässt und "anders als traditionell in den Sozialwissenschaften wird in der Dialektologie Repräsentativität eher durch qualitative Kriterien als durch solche der Mindestgruppengrösse gewährleistet" (Bellmann 1994: 35). Da aber für L2-Kompetenzen und insbesondere Akzentstärke, anders als für Dialektmerkmale, ${ }^{23}$ durchaus eine hohe individuelle Variation erwartbar ist, war es ein Anliegen dieser Studie, mehr als eine Sprecherin pro Ort zu berücksichtigen.

Die acht Sprecherinnen und Sprecher fügen sich problemlos in das von Bellmann (ebd.: 3739) geforderte Konzept des NaS ein: Sie sind ortsfest in dem Sinne, dass alle in der Stadt Bern bzw. St. Gallen aufgewachsen sind und wohnen, dass ihre Eltern meist je beide Stadtberndeutsch bzw. Stadt-St. Gallerdeutsch sprechen und dass sie keine zweite Muttersprache sprechen. Standarddeutsch und Französisch wurde von allen Sprechern in der Schule gelernt und regelmässig gesprochen. Tabelle 1 gibt Aufschluss über die Daten zu den einzelnen Sprecherinnen, insbesondere zum Alter ihres ersten Kontaktes zu Standarddeutsch und Französisch. Als Kontext dieses Erwerbs geben die meisten die Schule an, für Standarddeutsch vereinzelt auch das Fernsehen oder, im Fall von SG3, die Familie. ${ }^{24}$

\footnotetext{
23 Zumindest in der Schweiz, wo der Dialekt mit keinerlei Stigma behaftet ist.

${ }^{24}$ SG3 ist nicht zweisprachig aufgewachsen, war aber durch ihre entferntere Verwandtschaft mit den beiden Sprachen schon früh in Kontakt.
} 


\begin{tabular}{|c|c|c|c|c|}
\hline & Alter & Geschlecht & StdDT: erster Kontakt & FR: erster Kontakt \\
\hline SG1 & 21 & $\mathrm{w}$ & 4 & 11 \\
\hline SG2 & 23 & $\mathrm{~m}$ & 6 & 10 \\
\hline SG3 & 21 & $\mathrm{w}$ & 0 & 0 \\
\hline SG4 & 25 & $\mathrm{~m}$ & 3 & 11 \\
\hline BE1 & 23 & $\mathrm{~m}$ & 7 & 11 \\
\hline BE2 & 24 & $\mathrm{~m}$ & 7 & 11 \\
\hline BE3 & 25 & $\mathrm{w}$ & 7 & 3 \\
\hline BE4 & 28 & $\mathrm{w}$ & 5 & 11 \\
\hline
\end{tabular}

Tabelle 1: Profil der St. Galler und Berner Sprecher

\subsubsection{Material}

Anders als z. B. bei Strik/Cucchiarini/Binnenpoorte (2000: 582, 585), die für ihr Experiment verschiedene Aufgaben für zwei Sprechergruppen mit unterschiedlichem Sprachniveau verwenden, wurden für die vorliegende Studie die Aufgabenstellungen für alle Sprecherinnen gleich gehalten, um eine möglichst hohe Vergleichbarkeit und damit möglichst allgemeingültige Aussagen zu erlauben. Es wurde sowohl Spontan- als auch Lesesprache aufgenommen, um einen eventuellen Unterschied in Akzentstärke und Akzentmerkmalen kontrollieren zu können. Als Lesetext wurde die Fabel Nordwind und Sonne bzw. La bise et le soleil des griechischen Dichters Aesop gewählt, die in der Phonetik aus Gründen der Vergleichbarkeit regelmässig verwendet wird. Die Texte wurden dem Handbook of the IPA (vgl. The International Phonetic Association 1999/2003: 81, 89) entnommen. Eine wichtige Voraussetzung für das Elizitieren von Spontansprache war, dass die Aufgabe von der kognitiven Seite her möglichst einfach zu lösen sein sollte, ohne dass die Sprecher viel Energie und Konzentration auf den Inhalt aufwenden müssen. Als weitere Prämisse sollten emotionale oder persönliche sowie potentiell unangenehme Themen vermieden werden. So wurden die Sprecher gebeten, ihre Morgenroutine, vom Aufwachen bis zur Ankunft an der Universität oder der Arbeit, zu schildern - auf Standarddeutsch und Französisch.

\subsubsection{Rahmenbedingungen}

Die Texte wurden mit jeder Sprecherin allein, in ihrer Wohnung oder in ihrem Büro, aufgenommen. Dies sollte einerseits zur Unbefangenheit der Sprecherinnen beitragen, andererseits konnten so externe Lärmquellen vorwiegend ausgeschaltet werden. Vor der Aufnahme wurden die Sprecher nicht über die Fragestellung der Studie aufgeklärt. Um Stressgefühle zu vermeiden und die Sprecherinnen sukzessive an die Mikrophon-Situation zu gewöhnen, wurden ihnen die Aufgaben nach und nach vorgelegt, die einfacheren Aufgaben jeweils zuerst: Zunächst wurden die standarddeutschen Sprachproben aufgenommen, danach die Französischen; dabei lasen die Sprecher jeweils zuerst den Text vor, danach erst wurde Spontansprache elizitiert. Die Texte wurden ohne vorheriges Betrachten vorgelesen und auch die Aufgabe zur freien Rede wurde ohne längere Planung direkt aufgenommen.

Die Erhebung der Sprachdaten fällt zwar unter den Geltungsbereich des Beobachterparadoxons $^{25}$, was jedoch dadurch entschärft wird, dass die Exploratorin Standarddeutsch ebenfalls mit einem Deutschschweizer dialektalen Akzent spricht, ${ }^{26}$ und der Code Prestige/Stigma in der Schweizer Sprachsituation eine andere Rolle spielt als in Situationen, wie sie etwa für Labovs (2006) Kaufhausexperimente relevant waren oder in Deutschland die Verwendungen von Dialekt und Standardsprache bestimmen. Deshalb sollte die Problematik der Beobachtung, gerade im Bereich der Phonetik/Phonologie, die im

25 "[...] that our goal is to observe the way people use language when they are not being observed" (Labov 1972: $61)$.

${ }^{26}$ Vgl. die Forderungen Hotzenköcherles (1962b: 127) zum sprachlichen Verhalten der Exploratoren bei der Erhebung von Dialektdaten im Feld. 
Vergleich etwa zu Lexikon oder Syntax weniger bewusst prozessiert wird, nicht überschätzt werden. Dennoch kann nicht ausgeschlossen werden, dass z. B. die etwas unnatürlich klingenden, tendenziell eher "binnendeutsch" gefärbten Akzente der Sprecher BE1 und SG327 durch den nicht einer natürlichen Redesituation entsprechenden Aufnahmekontext hervorgerufen wurden.

\subsubsection{Technische Details}

Für die Tonaufnahmen diente ein Gerät der Marke Fostex, Modell FR-2LE. Zusätzlich wurde ein ansteckbares Mikrophon vom Typ Sennheiser MKE 2 p-c verwendet. ${ }^{28}$

Der einzige technische Eingriff, der in den Tondokumenten vorgenommen wurde, betrifft Ortsnamen und Dialektwörter, welche jeweils durch einen Ton der Frequenz $250 \mathrm{~Hz}$ ersetzt wurden. So entstanden 32 Stimuli, vier pro Sprecher, jeweils die Hälfte auf Standarddeutsch bzw. Französisch, vorgelesen bzw. spontan gesprochen. Die Länge der Stimuli liegt jeweils zwischen $21 \mathrm{~s}$ und $68 \mathrm{~s}$, was die bei Bauvois (1996: 297) besprochene Mindestlänge von 10$15 \mathrm{~s}$ zur Erkennung regionaler Sprachmerkmale erfüllt.

\subsection{Ablauf des Experiments}

Das Experiment wurde jeweils in Seminarräumen der jeweiligen Hochschulen durchgeführt. Vor dem Abspielen der Aufnahmen über Lautsprecher wurde den Probanden sowohl mündlich als auch schriftlich mitgeteilt, dass Deutschschweizer Dialektsprecher bezüglich ihrer Akzentstärke und ihrer dialektalen Herkunft beurteilt werden sollten.

Die deutschsprachigen Probanden hörten jeweils alle 32 Stimuli in zufälliger Reihenfolge, wobei die standarddeutschen vor den französischen präsentiert wurden. Während dem Zuhören sollte für jede Sprachprobe entschieden werden, aus welchem Dialektgebiet die jeweilige Sprecherin stammt. Der Fragebogen für die deutschsprachigen Probanden enthielt keine weiteren Angaben zur Sprecherherkunft - die Probanden mussten frei antworten. Insbesondere war unbekannt, wie viele Dialektgebiete in den Aufnahmen insgesamt vertreten waren. Die französischsprachigen Probanden hörten nur die 16 französischen Stimuli; ihr Fragebogen jedoch enthielt eine multiple-choice-Struktur, sie mussten also jeweils nur ankreuzen, ob der jeweilige Stimulus von einem Berner oder einem St. Galler stammt (vgl. dazu 4.4).

Das gesamte Experiment dauerte für die deutschsprachigen Probanden gut $30 \mathrm{~min}$, für die französischsprachigen etwa $20 \mathrm{~min}$.

\subsection{Pilotstudie}

Eine kleine Pilotstudie sollte das Untersuchungsdesign sowie die Fragebögen auf ihre Anwendbarkeit überprüfen: Die deutschsprachigen Pilot-Probanden, die über die Aufnahmeorte Bern und St. Gallen aufgeklärt war, verortete die meisten Stimuli korrekt, die deutschen Aufnahmen etwas besser als die französischen. Dies bestätigte das geplante Vorgehen, die Frage nach der dialektalen Herkunft im Experiment offen zu gestalten.

Die französischsprachigen Pilot-Probanden hörten nur die französischen Aufnahmen. Auf der ersten Fragebogenversion wurde die Frage nach der regionalen Herkunft, wie für die deutschsprachigen Probanden, offen gestellt, ebenso waren diese Personen nicht über die Aufnahmeorte aufgeklärt. Sie waren bei der Frage nach der regionalen Herkunft der Sprecher überfordert, in der Regel blieben die Antwortfelder leer. Dies erklärt sich nicht zuletzt durch

\footnotetext{
27 Vgl. dazu 5.2.

${ }^{28}$ Mein Dank geht an das Phonetische Laboratorium und das Phonogrammarchiv der Universität Zürich, die das Material freundlicherweise zur Verfügung gestellt haben.
} 
die Tatsache, dass Romands die Verschiedenheit Deutschschweizer Dialekte weniger stark wahrnehmen - Français fédéral ist Français fédéral. Deshalb wurde für das Experiment mit französischsprachigen Probanden die Frage nach dem Herkunftsdialekt der Sprecher nicht offen formuliert, sondern die beiden Optionen Bern und St. Gallen zur Auswahl gestellt. Die Probanden sollten, falls sie weder den Berner noch den St. Galler Dialekt erkannten, das erste Kreuz spontan setzen und dann versuchen, zwei verschiedene "Akzentgruppen" zu bilden. So konnte auch geprüft werden, ob Romands, falls sie die Sprecher nicht konkret verorten können, zumindest einen Akzentunterschied zwischen einem Berner und einem St. Galler wahrnehmen. Auch diese Art der Befragung wurde in einem Pretest auf ihre Anwendbarkeit überprüft und für angemessen befunden.

\subsection{Datenaufbereitung und -auswertung}

Dieses Kapitel liefert eine Vorbereitung auf die Darstellung der Resultate, indem genau dargelegt wird, wie die erhobenen Daten sortiert, kategorisiert und ausgewertet wurden. Für die Auswertung der Daten und das Erstellen der Graphiken wurde mit der Statistik-Software $R^{29}$ gearbeitet. Die zwei Probandengruppen müssen jeweils nach ihrer L1 unterschieden werden, da den deutschsprachigen Hörern eine andere Aufgabenstellung vorgelegt wurde, als den französischsprachigen.

\subsubsection{Daten frankophoner Probanden}

Da die französischsprachigen Probanden lediglich zwischen den Optionen Bern und St. Gallen entscheiden sollten, konnten einseitige Binomialtests angewendet werden. Tatsächlich entspricht die gestellte Situation dem klassischen Bernoulli-Modell mit zwei Resultaten: Erfolg (Erkennen der Herkunft des Sprechers in einem bestimmten Stimulus) und Misserfolg (falsches regionales Einordnen der Sprecherin).

Da angenommen werden musste, dass manche Probanden keine oder nur sehr beschränkte Kontakte zu Deutschschweizern pflegen, war die Aufgabenstellung differenziert gestellt worden: Falls sie nicht wussten, wie z. B. ein Berner Französisch spricht, so sollten sie versuchen, die Nennungen Bern und St. Gallen als zwei unterschiedliche "Akzentgruppen" zu betrachten. Damit wurden zwei Datensätze kreiert: Der Originaldatensatz, der die regionale Erkennung widerspiegelt und ein Datensatz, der nur die grundsätzliche perzeptuelle Unterscheidbarkeit zweier Akzente durch frankophone Probanden darstellt.

\subsubsection{Daten deutschsprachiger Probanden}

Bei den Deutschschweizer Probanden wurde die Frage nach der dialektalen Herkunft der Sprecher frei gestellt, es standen also keine multiple-choice-Antworten zur Verfügung. Die Probanden wussten insbesondere nicht, aus wie vielen verschiedenen Dialektgebieten die Sprecher stammen, was in einer hohen Variabilität der Antworten resultiert. Bei 32 Stimuli liegt für den Hörer die Annahme von mehr als zwei Akzenten nahe, was möglicherweise in einer Verzerrung hin zu einer hohen Variabilität der Antworten resultiert. Dass ein solches "freies Raten" die oben beschriebene Bernoulli-Situation überstrapaziert, ist offensichtlich. Deshalb wurden die Resultate in einem ersten Schritt regional gebündelt und deskriptiv in Kreisdiagrammen ausgewertet. In einem zweiten Schritt wurden die Daten wie in 4.5.1 beschrieben kodiert und mit einem Binomialtest analysiert, der Situation halber aber in drei verschieden breiten Versionen. Tabelle 2 gibt einen Überblick über die Antworten, die für jede dieser Versionen als identifiziert akzeptiert wurden, die Karte in Abbildung 2 stellt die drei unten näher erläuterten Kategorien in unterschiedlich transparenten Farbtönen dar. Die eindeutige Kategorisierung von Dialekträumen, die sich in der Realität als Kontinua

${ }^{29}$ Version 2.11.1, vgl. R Development Core Team (2010). 
präsentieren, ist selbstverständlich ein Konstrukt; ${ }^{30}$ gestützt auf die Grundlagen, die in 3.1.1 erarbeitet wurden, kann sich diese Kategorisierung jedoch - systematisch und der Schweizer Lautlandschaft gemäss - der Realität annähern.

\begin{tabular}{|l|l|l|}
\hline & akzeptiert für Berner Sprecher & akzeptiert für St. Galler Sprecher \\
\hline enge Kategorie & BE & SG \\
\hline mittlere Kategorie & BE & SG \\
& SO, FR & TG, SH, AP, (Nord-)OstCH \\
\hline breite Kategorie & BE & SG \\
& SO, FR & TG, SH, AP, (Nord)OstCH, \\
& BA, LU, AG, VS, UR, WestCH, & ZH, GR, GL, SZ \\
& Mittelland West & Mittelland Ost \\
\hline
\end{tabular}

Tabelle 2: Kategorisierung der Daten

Der Grossteil der Antworten versucht, den vermuteten dialektalen Akzent durch einen Kantonsnamen wiederzugeben. ${ }^{31}$ Die relativ seltenen Orts-, Tal- oder Regionennamen (z. B. Biel, Landwassertal, Berner Oberland) wurden somit auch in die Kantonskategorie umgewandelt, die Nennung eines Landesteils (z. B. Nordostschweiz, Mittelland) wurde beibehalten. Solche Dialektkategorisierungen widerspiegeln nicht zuletzt die linguistische Distanz des Hörers zum beurteilten Dialekt: Sprachliche Ausprägungen, die dem eigenen Dialekt nahe sind, werden differenzierter beurteilt als Varianten, mit welchen ein Hörer selten in Kontakt ist (vgl. Christen 2010: 273, Fussnote 8).

Die enge Kategorie akzeptiert nur die Antworten, die den Ausdruck Bern bzw. St. Gallen enthalten, was für die Berner Stimuli relativ unproblematisch ist, die St. Galler Stimuli hier aber weniger stark gewichtet: Wie unten in 5.2 besprochen wurden die Berner Sprecherinnen v. a. als "Bernerin" erkannt, die St. Galler Sprecher mehrheitlich als "Ostschweizer".

Die mittlere Kategorie zieht die unmittelbare dialektale Umgebung der hier betrachteten Dialekte mit ein; das rechtfertigt für BE den Einbezug der benachbarten Regionen FR und SO, jedoch nicht den (auch sprachlich) viel südlicheren Kanton VS, ebenso wenig die zu jeweils einem Teil in der West/Ost- bzw. (Süd-)West/Nordost-Grauzone liegenden Sprachgebiete AG, LU, BA. Für SG bedeutet dies die Hinzunahme der Dialektgebiete von $\mathrm{SH}, \mathrm{TG}$, AP, jedoch nicht die davon abzugrenzenden Dialekte von $\mathrm{ZH}$, ebenso wenig die Bündner Dialekte, die teilweise in der West/Ost-Grauzone liegen. Hier wird aus pragmatischen Gründen auch die häufigste Antwort für St. Galler Sprecher, Ostschweiz, akzeptiert, die sich im alltäglichen Sprachgebrauch hauptsächlich auf die genannten Kantone bezieht, also ZH explizit nicht mit einschliesst. Ob Ostschweiz die Bündner Dialekte für diese mittlere Kategorisierung mit einschliessen sollte, kann kontrovers diskutiert werden; hier werden sie aufgrund ihrer partiellen Grauzone-Stellung vorläufig ausgeschlossen (vgl. 3.1.1). Aus mehreren in 3.1.1 präsentierten Argumenten geht hervor, dass $\mathrm{ZH}$, wenn auch das Gebiet nicht in der West/Ost-Grauzone liegt, als zulässige (mittlere) Identifizierung von St. Galler Sprecherinnen nicht in Frage kommt, da die Zürcher Mundarten von denen der "eigentlichen"

\footnotetext{
${ }^{30}$ Zur Problematik der Einteilung von Dialekträumen vgl. Christen (2010: 269-272).

31 Da die Mehrheit der Kantone denselben Namen wie ihre Hauptstadt tragen, kann prinzipiell nicht ausgeschlossen werden, dass bei manchen Antworten die Stadt und nicht der Kanton gemeint war. Dieses Problem kann jedoch mit Christen (2010: 273, Fussnote 10; Hervorh. im Orig.) relativiert werden: "Dass es sich bei Bezeichnungen wie Zürichdeutsch um Kategorisierungen auf dem Niveau von Kantonen und nicht von (gleichnamigen) Städten handelt, wird daran ersichtlich, dass es für letzteres die Bezeichnung Stadtzürcher Dialekt gibt. Der Dialekt der Städte Zürich, Basel, Bern, Luzern usw. kann dabei ohne Zweifel metonymisch für eine umfassendere natürliche Kategorie Zürichdeutsch usw. stehen, muss dies aber nicht." Tatsächlich treten beim vorliegenden Perzeptionsexperiment auch ein paar wenige Antworten vom Typ Stadtberndeutsch auf.
} 
Ostschweiz beträchtlich abweichen - es sei dabei insbesondere an die /a/- und /r/-Qualität des Zürichdeutschen, im Gegensatz zu den Ostschweizer Dialekten, erinnert.

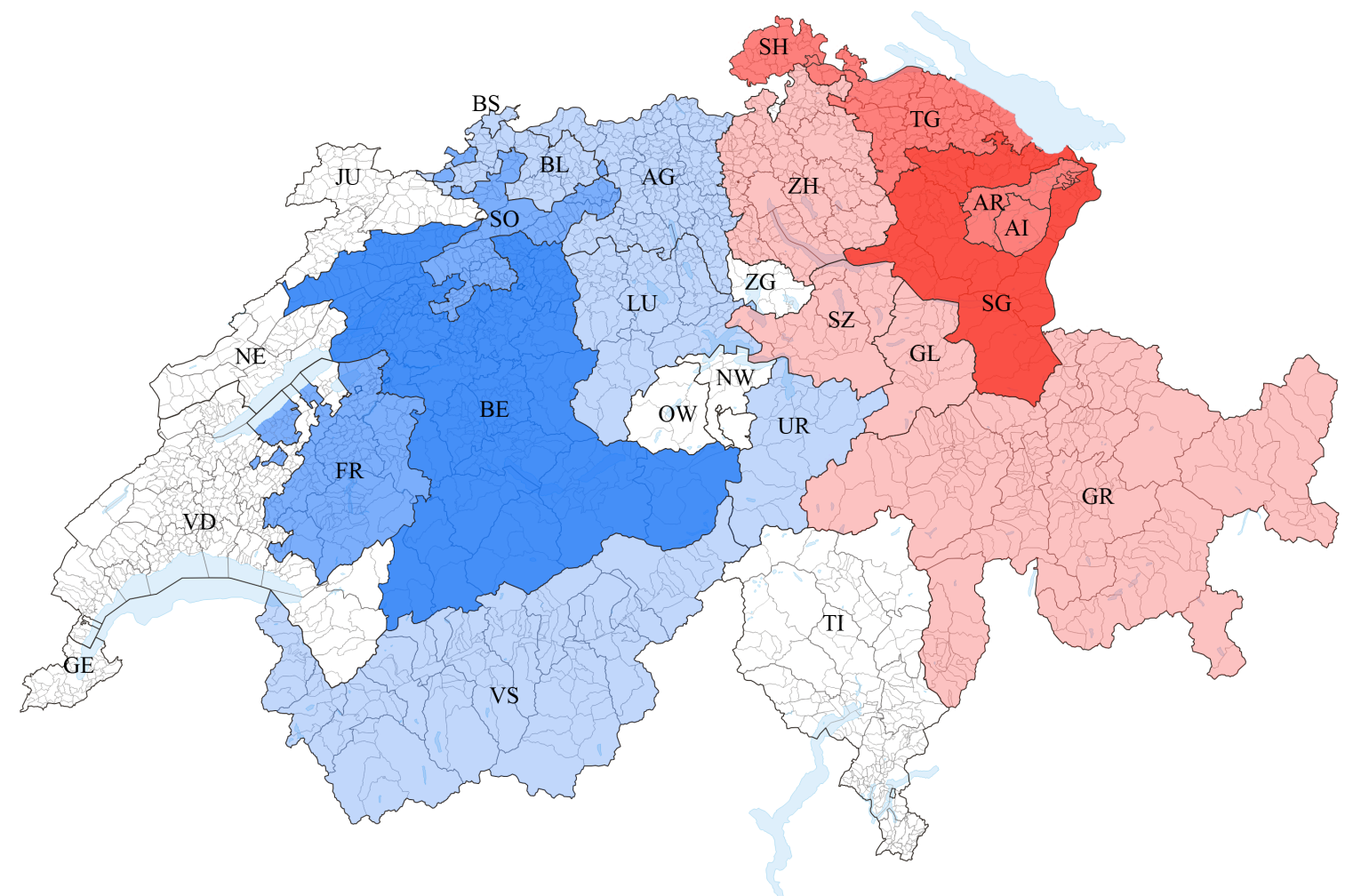
Abbildung 2: Kategorien "eng", "mittel" und "breit", gekennzeichnet durch steigende Transparenz der
Farbtöne; West/Ost-Kontrast

Die breite Kategorie zielt auf einen globaleren West/Ost-Kontrast ab und vernachlässigt hier die tendenziell sekundären Nord/Süd-Gegensätze, was das Hinzufügen der Dialekte von BA, AG, LU, VS, UR zum Westen rechtfertigt: Diese Gebiete liegen bei Isoglossenbündeln, wenn sie nicht ganz zum westlichen Teil der Schweiz gehören, immer nur zu einem Teil in der Grauzone. Zum Osten werden hier zusätzlich die Dialekte von ZH und GR gezählt. Ebenso können damit die Dialekte von SZ und GL hinzugenommen werden, die zumindest beim "reinen" West/Ost-Gegensatz klar zum Osten gehören, für die "abgedrehte" (Süd)West/Nordost-Variante aber zum grössten Teil in der Grauzone liegen. Weiter wurden in dieser breiten Kategorie auch die Antworten Ostschweiz, Westschweiz als identifiziert gewertet (vgl. 3.1.1).

Dass aus der Versuchsanordnung ohne multiple-choice-Antworten hier tendenziell hohe pWerte, also eher nur wenige signifikante Resultate folgen, ist offensichtlich - die visuelle Darstellung der Daten in Kreisdiagrammen und prozentuale Erkennungsraten bieten deshalb zusätzlich einen deskriptiven Ansatz. Hierfür wurde die mittlere Kategorie als geeignete Basis gewählt, die Antworten $B E, S O, F R$ sowie $S G, T G, S H, A P$, (Nord-)Ostschweiz wurden also mit identifiziert kodiert. Die für die breite Kategorie zusätzlich akzeptierten Antworten fielen in einen Graubereich und alle anderen Antworten wurden mit nicht identifiziert kodiert.

\section{$5 \quad$ Präsentation und Diskussion der Resultate}

\subsection{Frankophone Probanden}

Die Daten zur regionalen Einordnung zeigen, dass die Sprecher als Gruppe und über beide Konditionen hinweg signifikant richtig zugeteilt wurden; für einzelne Sprecher gilt dies aber mit Signifikanzniveau $\alpha=0.05$ und nach Bonferroni-Korrektur nicht (vgl. Tabelle 3; p-Werte 
statistisch signifikanter Resultate sind rot markiert). Werden die Resultate zur Lese- und Spontansprache einzeln betrachtet, so fällt auf, dass Aktzenterkennung nur für die Lesesprache-Kondition signifikant ist. Dies bildet ein Resultat ab, das in Kolly (2011) diskutiert wird: Die Akzentstärke der Sprecher dieser Stichprobe wird in Lesesprache als stärker wahrgenommen, als in spontansprachlichen Stimuli.

Die Daten zur grundsätzlichen Möglichkeit der Akzentunterscheidung fördern mehr Signifikanzen zu Tage: Nicht nur wurden die Sprecher als Gruppe richtig auseinander gehalten, die Werte sind auch für Spontan- und Lesesprache einzeln signifikant und sogar für zwei Sprecher einzeln, über beide Konditionen hinweg (vgl. Tabelle 4). SG1 wird, wie auch durch Deutschschweizer Hörerinnen, am leichtesten kategorisiert. Für BE3 jedoch gilt das nicht in diesem Ausmass. BE2, der von den deutschsprachigen Probanden sehr leicht als Berner erkannt wurde, konnte von den französischsprachigen Hörern nur schwer kategorisiert werden (vgl. 5.2).

\begin{tabular}{|l|c|c|c|}
\hline & Lesesprache & Spontansprache & Total \\
\hline SG1 & 0.1316 & 0.0577 & 0.0192 \\
\hline SG2 & 0.0059 & 0.9987 & 0.5627 \\
\hline SG3 & 0.0059 & 0.9423 & 0.2148 \\
\hline SG4 & 0.1316 & 0.0207 & 0.0083 \\
\hline BE1 & 0.7483 & 0.0207 & 0.1341 \\
\hline BE2 & 0.1316 & 0.1316 & 0.0404 \\
\hline BE3 & 0.1316 & 0.0577 & 0.0192 \\
\hline BE4 & 0.0577 & 0.7483 & 0.2148 \\
\hline Total & $\mathrm{p}<0.02$ & 0.0483 & $\mathrm{p}<0.005$ \\
\hline
\end{tabular}

Tabelle 3: Akzent-Lokalisierung durch frankophone Probanden, p-Werte je Sprecher und Kondition, gerundet auf 5 Stellen

\begin{tabular}{|l|c|c|c|}
\hline & Lesesprache & Spontansprache & Total \\
\hline SG1 & 0.0207 & 0.0059 & $\mathrm{p}<0.005$ \\
\hline SG2 & 0.0059 & 0.9793 & 0.3179 \\
\hline SG3 & 0.0059 & 0.9423 & 0.2148 \\
\hline SG4 & 0.1316 & 0.0207 & 0.0083 \\
\hline BE1 & 0.4119 & 0.0207 & 0.0404 \\
\hline BE2 & 0.4119 & 0.4119 & 0.3179 \\
\hline BE3 & 0.0207 & 0.0207 & $\mathrm{p}<0.005$ \\
\hline BE4 & 0.0059 & 0.4119 & 0.0192 \\
\hline Total & $\mathrm{p}<0.02$ & $\mathrm{p}<0.02$ & $\mathrm{p}<0.005$ \\
\hline
\end{tabular}

Tabelle 4: Akzentunterscheidung durch frankophone Probanden, p-Werte je Sprecher und Kondition, gerundet auf 5 Stellen

Angesichts der vielen Schwierigkeiten, dem relativ schwachen Interesse und den eher negativen Einstellungen, die für viele frankophone Schweizer mit dem Erwerb des Standarddeutschen einhergehen (vgl. Muller 1998, Fuchs/Werlen 1999), schien die Hypothese, dass diese Hörergruppe Deutschschweizer Akzente auseinander halten und lokalisieren kann, etwas gewagt. Die Resultate aus den statistischen Tests liefern hier ein spannendes Bild zur Wahrnehmung von Deutschschweizer Dialekten durch französischsprachige Schweizer. Zusätzlich gestützt werden die Resultate dadurch, dass die totale Anzahl richtig erkannter Stimuli für jeden Sprecher grösser ist als (oder in einem Fall gleich gross ist wie) die Anzahl derer, die nicht erkannt wurden. ${ }^{32}$ Ganz besonders hervorzuheben ist die Tatsache, dass zwei Hörer, die als L1 ausschliesslich Französisch angeben, nur einen resp. zwei Stimuli falsch zugeordnet haben. Grundsätzlich darf aber nicht

\footnotetext{
32 Für den Datensatz, der nur auf die Unterscheidbarkeit von zwei Akzenten abzielt, ist hier "identifiziert" nicht im wörtlichen Sinne zu verstehen; vielmehr ist damit gemeint, dass der jeweilige Stimulus von den Stimuli der anderen "Akzentgruppe" unterschieden wurde.
} 
vergessen werden, dass die Stichprobe sowohl der acht Sprecher als auch die der 20 Probanden relativ klein ist und die vorgestellten Resultate als Pilotstudie betrachtet werden sollten.

Erstaunlich ist, dass mehrere Sprecher beim Vorlesen gut erkannt wurden, deren Spontansprache aber am schlechtesten über alle Sprecher - oder umgekehrt (vgl. Tabelle 3). Für SG2 kann dies dadurch erklärt werden, dass er in seiner Schilderung der Morgenroutine auf Französisch nur sehr zögernd und wenig spricht: Er war zum Zeitpunkt der Aufnahme erkältet, was die heisere, knarrende Stimme und das langsame Sprechtempo erklärt. Der $32 \mathrm{~s}$ lange Stimulus enthält viele relativ lange Pausen, was die Erkennbarkeit seines Akzents rein von der Quantität des Sprachmaterials her beeinträchtigt. Auch bei BE1 ist der Unterschied zwischen der Erkennbarkeit der freien und der vorgelesenen Sprachprobe gross: Seine Spontansprache wird signifikant erkannt, seine Lesesprache jedoch von allen Sprechern am schlechtesten identifiziert. Der Grund dafür könnte darin liegen, dass BE1 sehr schnell vorliest und ihm dabei zahlreiche Aussprachefehler unterlaufen, die für Deutschschweizer Sprecher nicht unbedingt typisch sind: bei einigen Wörtern wird die letzte Silbe verschluckt, mehrere Vokale werden fälschlicherweise nasalisiert (z. B. [mãtõ] statt [mãto] für manteau 'Mantel'). In der Spontansprache unterlaufen ihm zwar Grammatikfehler, jedoch keine auffälligen Aussprachefehler.

\subsection{Deutschsprachige Probanden}

Die Resultate der Binomialtests für die drei verschieden breiten Kategorien sind in den Tabellen 5 (eng), 6 (mittel) und 7 (breit) dargestellt (Bonferroni-korrigiert). Dabei werden nur wenige signifikante Resultate verzeichnet, in der engen Kategorie gar keine (p-Werte statistisch signifikanter Resultate sind rot markiert, vgl. Tabellen 5-7). Vorab die wichtigste Erkenntnis aus den statistischen Tests: Berner und St. Galler Sprecher können beim Vorlesen von standarddeutschen Texten als aus der Region BE, FR, SO bzw. als aus der (Nord)Ostschweiz stammend identifiziert werden (vgl. Tabelle 6).

Als Erstes ist zu bemerken, dass die Anzahl signifikanter Resultate mit der wachsenden Breite der Kategorien erwartungsgemäss steigt. Diese Anzahl ist mit den Resultaten der Binomialtests aus 5.1 wegen der unterschiedlichen Versuchsanordnung nicht direkt vergleichbar, wohl aber die grundsätzliche Erkennbarkeit verschiedener Sprecher, wie sie weiter unten diskutiert wird.

Zweitens sticht ins Auge, dass die Erkennungsraten französischsprachiger Stimuli hier nicht signifikant sind. Auch diese Erkenntnis ist mit den Binomialtests aus 5.1 aufgrund der unterschiedlichen Fragestellung und den daraus resultierenden Antworttypen nicht direkt vergleichbar. Offensichtlich ist aber, dass es für Deutschschweizer Hörer schwieriger ist, einen bestimmten dialektalen Akzent in französischen Stimuli zu identifizieren, als in standarddeutschen. Die deskriptive Darstellung der Daten erlaubt hier eine detailliertere Sicht auf die Tatsachen (vgl. Abbildungen 3-10).

Als Drittes ist hervorzuheben, dass die dialektalen Akzente der Sprecher in lesesprachlichen Stimuli besser erkannt wurden als in spontansprachlichen: Das Resultat für die standarddeutsche Lesesprache über alle Sprecher hinweg ist hochsignifikant, wenn man die mittlere und die breite Kategorie betrachtet. Dies widerspiegelt das Resultat der französischsprachigen Hörer und, wie in 5.1 bemerkt, die Tatsache, dass die Akzentstärke der Sprecher in der Lesesprache als stärker wahrgenommen wird, als in den spontansprachlichen Stimuli (vgl. Kolly 2011). Die Sprecher SG1 und BE2 sind global am leichtesten als St. Gallerin/Berner identifizierbar und werden signifikant als Ostschweizerin/Westschweizer erkannt. Dies wird dadurch bestätigt, dass die beiden Sprecher im Standarddeutschen wie im Französischen von allen den stärksten Akzent haben (zur Akzentstärke vgl. Kolly 2011). 


\begin{tabular}{|l|c|c|c|c|c|}
\hline & \multicolumn{2}{|c|}{ Standarddeutsch } & \multicolumn{2}{c|}{ Französisch } & \multirow{2}{*}{ Total } \\
\cline { 2 - 5 } & Lesesprache & Spontansprache & Lesesprache & Spontansprache & \\
\hline SG1 & 0.9997 & 1 & 1 & 1 & 1 \\
\hline SG2 & 1 & 1 & 1 & 1 & 1 \\
\hline SG3 & 1 & 1 & 1 & 1 & 1 \\
\hline SG4 & 1 & 1 & 0.9865 & 0.9980 & 1 \\
\hline BE1 & 1 & 1 & 0.8296 & 0.3939 & 0.0342 \\
\hline BE2 & 0.0111 & 0.0524 & 1 & 1 & 1 \\
\hline BE3 & 0.1144 & 0.9987 & 0.9980 & 1 & 0.9405 \\
\hline BE4 & 0.0111 & 0.0045 & 1 & 1 & 1 \\
\hline Total & 1 & 1 & &
\end{tabular}

Tabelle 5: Enge Akzent-Lokalisierung durch deutschsprachige Probanden, p-Werte je Sprecher und Kondition, gerundet auf 5 Stellen

\begin{tabular}{|l|c|c|c|c|c|}
\hline & \multicolumn{2}{|c|}{ Standarddeutsch } & \multicolumn{2}{c|}{ Französisch } & \multirow{2}{*}{ Total } \\
\cline { 2 - 5 } & Lesesprache & Spontansprache & Lesesprache & Spontansprache & \\
\hline SG1 & $\mathrm{p}<0.001$ & 0.0052 & 0.9332 & 0.9620 & 0.0090 \\
\hline SG2 & 0.4469 & 0.6556 & 1 & 1 & 1 \\
\hline SG3 & 0.7478 & 1 & 0.8898 & 1 & 1 \\
\hline SG4 & 0.2522 & 1 & 1 & 1 & 1 \\
\hline BE1 & 1 & 0.9999 & 0.9865 & 0.9955 & 1 \\
\hline BE2 & 0.0052 & 0.0290 & 0.8296 & 0.2950 & 0.0129 \\
\hline BE3 & 0.1144 & 0.9928 & 1 & 1 & 1 \\
\hline BE4 & 0.0111 & 0.0045 & 0.9955 & 1 & 0.8752 \\
\hline Total & $\mathrm{p}<0.01$ & 0.9987 & 1 & 1 & 1 \\
\hline
\end{tabular}

Tabelle 6: Mittlere Akzent-Lokalisierung durch deutschsprachige Probanden, p-Werte je Sprecher und Kondition, gerundet auf 5 Stellen

\begin{tabular}{|l|c|c|c|c|c|}
\hline & \multicolumn{2}{|c|}{ Standarddeutsch } & \multicolumn{2}{c|}{ Französisch } & \multirow{2}{*}{ Total } \\
\cline { 2 - 5 } & Lesesprache & Spontansprache & Lesesprache & Spontansprache & \\
\hline SG1 & $\mathrm{p}<0.001$ & $\mathrm{p}<0.001$ & 0.5540 & 0.6583 & $\mathrm{p}<0.05$ \\
\hline SG2 & 0.0220 & 0.0407 & 0.9968 & 0.9997 & 0.8268 \\
\hline SG3 & 0.4469 & 1 & 0.8296 & 0.9995 & 1 \\
\hline SG4 & 0.0705 & 1 & 0.9968 & 1 & 1 \\
\hline BE1 & 0.8856 & 0.9889 & 0.7950 & 0.8296 & 0.9926 \\
\hline BE2 & $\mathrm{p}<0.001$ & $\mathrm{p}<0.001$ & 0.2483 & 0.0524 & $\mathrm{p}<0.05$ \\
\hline BE3 & 0.0023 & 0.8597 & 0.9980 & 1 & 0.9910 \\
\hline BE4 & 0.0023 & 0.0019 & 0.8898 & 1 & 0.3675 \\
\hline Total & $\mathrm{p}<0.01$ & 0.3343 & 0.9997 & 1 & 0.9272 \\
\hline
\end{tabular}

Tabelle 7: Breite Akzent-Lokalisierung durch deutschsprachige Probanden, p-Werte je Sprecher und Kondition, gerundet auf 5 Stellen

Werden die p-Werte etwas näher betrachtet, so geht aus allen drei Kategorisierungen hervor, dass die Berner Sprecher generell besser erkannt wurden. Dabei muss als Erstes an die Übergewichtung von Berner Probanden gegenüber Ostschweizer Dialektsprechern im Experiment erinnert werden: Die "linguistische[...] Distanz zu sprachlichen Ausprägungen" (Christen 2010: 273, Fussnote 8) spielt bei Dialektkategorisierungen eine Rolle, was eine Erklärung für die genauere Identifizierung der Berner Sprecher gegenüber den St. Gallern bietet: Bei Varietäten, die der eigenen ähnlich sind, nimmt der Hörer mehr Unterschiede wahr - "aus der Ferne dagegen mögen Sprecherinnen und Sprecher aus dem Schaffhausischen und dem Thurgau recht ähnlich in den Ohren klingen, was die Betroffenen selbst natürlich ganz anders sehen..." (Christen 2005: 21). Auffällig ist aber auch, wie schon in 4.5.2 angedeutet, dass Berner v. a. als "Berner" erkannt wurden, St. Galler mehrheitlich als "Ostschweizer". Der Kanton Bern scheint in den mentalen Repräsentationen der Deutschschweizer ein eigenständiges (Dialekt)gebiet darzustellen, wobei die Ostschweizer bzw. die Nordostschweizer Dialekte eher als "Block" wahrgenommen werden. Auch Christens (2010: 277-278) Untersuchung bestätigt den speziellen Status der Kategorie Ostschweiz, die als Dialektbenennung in ähnlicher Weise wie Kantonsbezeichnungen und sehr viel häufiger als 
andere Namen von Landesteilen (Westschweiz, Nordschweiz usw.) verwendet wird. An dieser Stelle ist auch erwähnenswert, dass drei der deutschsprachigen Hörer bei der Angabe ihrer L1 nicht einen Kanton oder einen Gemeinde angegeben haben, sondern explizit "Ostschweizer Dialekt" - andere Landesteile traten in einem solche Kontext nie auf. Bei Christen (ebd.) wird als Erklärung auch eine gewisse Kontrastarmut zwischen den einzelnen Ostschweizer "Kantonsdialekten" angegeben. Ob nun die hier evidente Übergewichtung der "kantonalen" Antwort "St.-Gallerdeutsch" gegenüber anderen Ostschweizer Kantonen daran liegt, dass die St. Galler wirklich als solche erkannt wurden, oder ob St. Gallerdeutsch als Prototyp für die Ostschweizer Dialekte figuriert, bleibt unklar.

Die Resultate weisen auf beträchtliche Variabilität in der Erkennbarkeit der dialektalen Akzente verschiedener Sprecher hin. Im Folgenden werden die Erkennungsraten der einzelnen Sprecher näher betrachtet, wobei die Resultate der Binomialtests durch deskriptive Darstellungen der Daten zu den einzelnen Sprechern ergänzt und diskutiert werden. Kreisdiagramme basieren auf der mittleren Kategorisierung der Daten (vgl. 4.5.2). Gründe für die bessere oder schlechtere Identifizierbarkeit mancher Sprecher werden hier auf auditiver Basis diskutiert; genauere akustische Analysen der jeweiligen Sprachproben wären eine spannende Ergänzung der Resultate, würden aber den Rahmen des vorliegenden Artikels sprengen.

Resultate zu SG1 Die Sprecherin SG1 gehört zu den am leichtesten erkennbaren Sprechern. Bei der mittleren und breiten Kategorisierung wird ihr Akzent in Lesesprache am leichtesten und insbesondere signifikant erkannt. Die mittlere und breite Kategorie präsentieren signifikante p-Werte für beide standarddeutschen Stimuli, was auch an den Kreisdiagrammen exemplifiziert wird (vgl. Tabellen 5-7 sowie Abbildung 3). Die Identifizierung der französischen Stimuli erreicht zwar in den Binomialtests keine Signifikanz, die Diagramme zeigen aber, dass SG1 jeweils von etwa 40\% der Probanden als (Nord-)Ostschweizerin erkannt wurde, was angesichts der freien Versuchsanordnung eine relativ hohe Erkennungsrate darstellt - bei Einbezug der "Grauzone", die einen West/Ost Gegensatz erfasst, steigt der Wert auf 50\%. Für beide Sprachen bestätigt sich die Tendenz, dass der Akzent in Lesesprache besser erkannt wird, für das Französische jedoch nur ganz knapp. 
Lesesprache $D(n=56)$

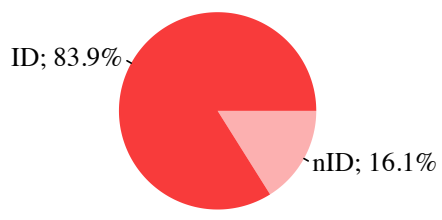

Lesesprache $\mathbf{F}(\mathbf{n}=\mathbf{5 4})$

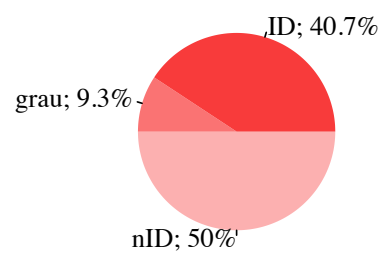

Spontansprache D $(\mathbf{n}=\mathbf{5 6})$

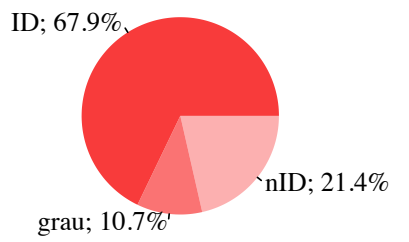

Spontansprache $\mathbf{F}(\mathbf{n}=\mathbf{5 4})$

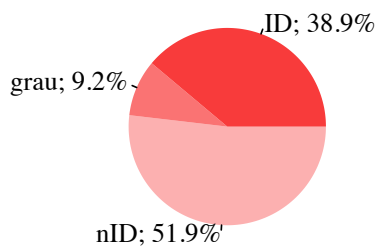

Abbildung 3: Identifizierbarkeit der Sprecherin SG1;

$I D=$ identifiziert, $n I D=$ nicht identifiziert, grau = identifiziert als "Ostschweizerin"

Resultate zu SG2 Der Sprecher SG2 wurde aufgrund französischer Stimuli oft falsch identifiziert, seine standarddeutsche Sprache jedoch wurde tendenziell als von einem Ostschweizer im weiteren Sinne (d. h. breite Kategorie) stammend erkannt (vgl. Abbildung 4, Segmente $I D+$ grau). Auch SG2 wird aufgrund der Lesesprache generell besser identifiziert als beim spontanen Sprechen (vgl. Tabellen 5-7 sowie Abbildung 4). Erwähnenswert ist hier der Modalwert ${ }^{33}$ "Ostschweiz" und die zweithäufigste Antwort "St. Gallen" für die standarddeutschen Stimuli. SG2 spricht im Französischen im Gegensatz zu den anderen St. Galler Sprechern für den /r/-Laut meist keinen uvularen (stimmhaften) Vibranten, sondern einen uvularen stimmlosen Frikativ $[\chi]$. Vokale spricht er tendenziell offener aus als die anderen St. Galler Sprecherinnen und Sprecher. Diese beiden Tatsachen erklären die vielen Fehlidentifizierungen seiner französischsprachigen Stimuli.

\footnotetext{
33 Der Modalwert bezeichnet in der Statistik den frequentesten Wert, d. h. hier die am häufigsten auftretende Angabe der Hörer zur dialektalen Herkunft des Sprechers.
} 
Lesesprache $\mathrm{D}(\mathrm{n}=\mathbf{5 6})$

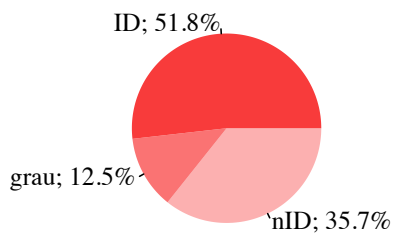

Lesesprache $\mathbf{F}(\mathbf{n}=\mathbf{5 5})$

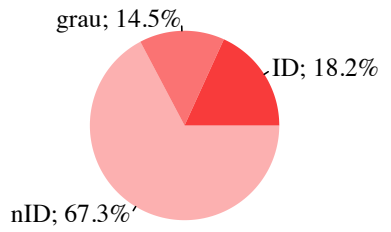

Spontansprache $D(n=56)$

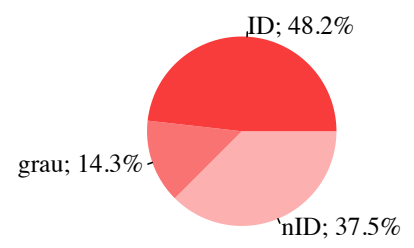

Spontansprache $\mathbf{F}(\mathbf{n}=\mathbf{5 4})$

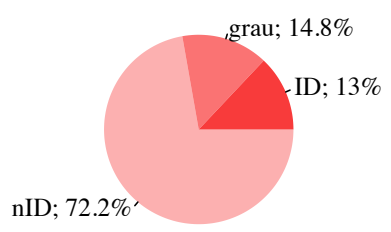

\section{Abbildung 4: Identifizierbarkeit des Sprechers SG2, $I D=$ identifiziert, $n I D=$ nicht identifiziert, grau = identifiziert als "Ostschweizer"}

Resultate zu SG3 Die Sprecherin SG3 wurde im Vergleich zu den anderen Sprechern im Standarddeutschen weniger leicht erkannt (vgl. Tabellen 5-7). Vor diesem Hintergrund erstaunt, dass ihre französischen Stimuli sie vergleichsweise leicht identifizieren. Besonders auffällig ist, dass der spontansprachliche standarddeutsche Stimulus schlechter erkannt wurde, als der vorgelesene französische. Eine mögliche Erklärung dafür ist der sich an eine "binnendeutsche" Aussprache annähernde Akzent dieser Sprecherin beim Deutschsprechen. ${ }^{34}$ Dieser kann ihre dialektale Herkunft zumindest beim Vorlesen zwar nicht für alle Hörer verschleiern, da sie immerhin von einem Grossteil der Probanden als Ostschweizerin erkannt wurde (den Modalwert bildet hier die Antwort "Ostschweiz"). Die allgemein hohe Variabilität der Zuordnungen zu diesem Stimulus betont aber die Schwierigkeit, diesen ambigen Akzent zu identifizieren. In den französischen Aufnahmen spricht SG3 im Vergleich zu den anderen Sprechern noch höhere, extrem geschossene Vokale, womit sie sich als Ostschweizerin erkennbar macht. Beim Betrachten der Abbildung 5 sticht vor allem ins Auge, dass im Gegensatz zu den Daten zu SG1 und SG2 nicht jeweils die deutschen und die französischen Stimuli gepaart auftreten, sondern jeweils die vorgelesenen und die frei gesprochenen. Aufgrund der Ausführungen oben muss bis auf weiteres angenommen werden, dass dies nicht aus einem Zusammenhang zwischen jeweils den beiden vorgelesenen und den beiden frei gesprochenen Stimuli jeder Sprache entsteht, sondern durch die Tatsache, dass die standarddeutschen Stimuli im Vergleich zu den anderen Sprechern ungewöhnlich selten und die französischen Stimuli ungewöhnlich leicht erkannt wurden.

\footnotetext{
${ }^{34}$ Konsequente /r/-Vokalisierungen zu Schwa [e], "ach-Laut" [x] durchgehend zu weit vorne, als [ç ], realisiert (vgl. dazu Hove (2002: 177) und 3.2.2.1). SG3 gibt als einzige Sprecherin an, von Geburt an Kontakt zu Standarddeutsch gehabt zu haben, dies in ihrer entfernteren Verwandtschaft.
} 
Lesesprache $D(n=56)$

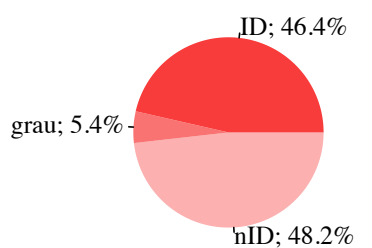

Lesesprache $F(n=54)$

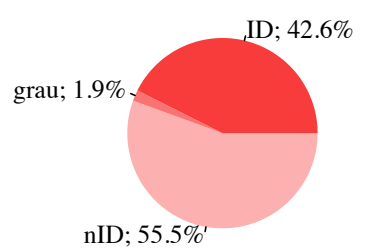

Spontansprache D $(\mathbf{n}=\mathbf{5 4})$

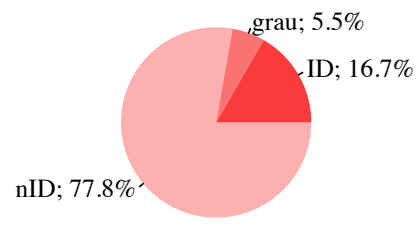

Spontansprache $\mathbf{F}(\mathbf{n}=\mathbf{5 5})$

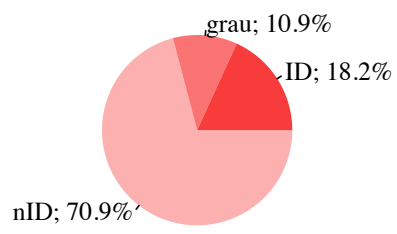

Abbildung 5: Identifizierbarkeit der Sprecherin SG3,

$I D=$ identifiziert, $n I D=$ nicht identifiziert, grau = identifiziert als "Ostschweizerin"

Resultate zu SG4 Auch für den Sprecher SG4 fördern die statistischen Tests keine signifikanten Erkennungsraten zutage - für die standarddeutsche Lesesprache nur knapp nicht (vgl. auch Abbildung 6, nach der SG4 beim Vorlesen auf Standarddeutsch angesichts der Fülle an möglichen Antworten mit etwa 55\% ziemlich leicht und insbesondere leichter als SG2 und SG3 erkannt wurde). Die spontansprachlichen Stimuli jedoch, der standarddeutsche wie der französische, waren vergleichsweise schwierig zuzuordnen. Auffällig ist auch, dass, wie bei SG3, der frei gesprochene standarddeutsche Stimulus schlechter erkannt wurde, als der vorgelesene französische, was die Tendenz besserer Identifizierbarkeit vorgelesener Rede besonders unterstreicht. Interessant ist, dass SG4 durch Hörer mehrfach als "Romand" kategorisiert wurde. Diese Nennung tritt aber beim standarddeutschen Stimulus fast doppelt so häufig auf, wie beim französischen. Die Annahme ist hier, dass die im Vergleich zu den anderen St. Galler Sprechern noch weiter vorne im Vokaltrakt gesprochenen /a/-Laute sowie das vergleichsweise schnelle und relativ fehlerfreie Vorlesen, gekoppelt an den doch erkennbar nicht-binnendeutschen Akzent diese Antwort elizitieren - beim standarddeutschen Stimulus ungleich stärker, weil das Französisch des Sprechers für die meisten der Hörer doch erkennbar nicht native-like ist. 
Lesesprache $D(n=56)$

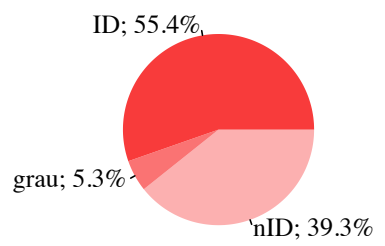

Lesesprache $\mathbf{F}(\mathbf{n}=\mathbf{5 5})$

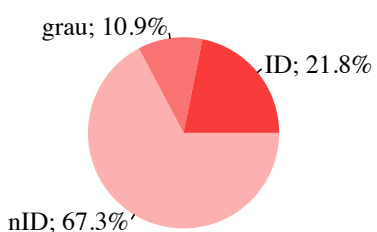

Spontansprache $\mathrm{D}(\mathrm{n}=\mathbf{5 6})$

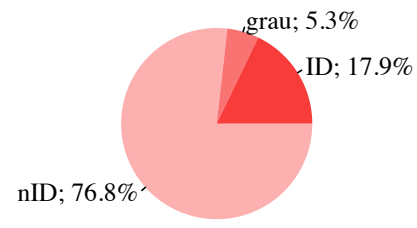

Spontansprache F $(\mathbf{n}=\mathbf{5 4})$

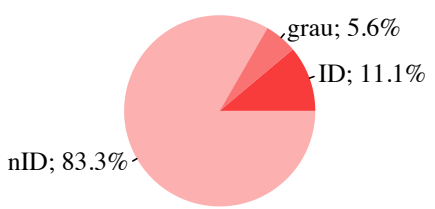

Abbildung 6: Identifizierbarkeit des Sprechers SG4, $I D=$ identifiziert, $n I D=$ nicht identifiziert, grau = identifiziert als "Ostschweizer"

Resultate zu BE1 Auch die standarddeutschen Stimuli des Sprechers BE1 waren vergleichsweise schwierig zu lokalisieren (vgl. Tabellen 5-7). Besonders auffällig ist, dass die französischsprachigen Stimuli besser erkannt wurden als die standarddeutschen. Ähnlich wie bei SG3 könnte die im Vergleich zu den französischen so tiefe Erkennungsrate für die standarddeutschen Stimuli auch hier an einem leicht "binnendeutsch" klingenden Akzent liegen. Die Kombination von nach Berner Art eher tief gesprochenen, offenen Vokalen mit uvularen bzw. zu Schwa [e] vokalisierten /r/-Lauten sowie die etwas zu weit vorne gesprochenen "ach-Laute" $[\mathrm{x}]$ als [ $\mathrm{c}]$ mag auf die Probandinnen verwirrend gewirkt haben. Im Französischen spricht BE1 die Vokale generell auch eher offen, seine Erkennbarkeit als Berner wird durch keine offensichtlich nicht-bernischen Lautvorkommnisse gestört. Weiter fällt auf, dass bei den standarddeutschen Stimuli die spontansprachlichen besser erkannt wurden, als die vorgelesenen (vgl. Abbildung 7). Dies wird durch einen breiten Graubereich (Erkennung von BE1 als Westschweizer) zur Lesesprache teilweise nuanciert. Auch bei BE1 bestätigt die bessere Erkennbarkeit der Lesesprache die allgemeine Tendenz. 
Lesesprache $D(n=56)$

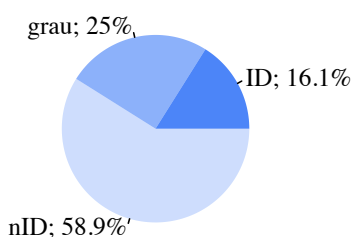

Lesesprache $\mathbf{F}(\mathbf{n}=53)$

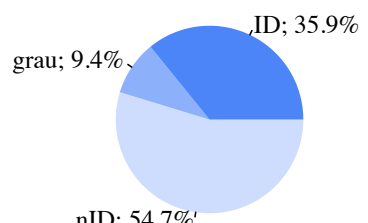

nID; $54.7 \%$
Spontansprache $D(n=56)$

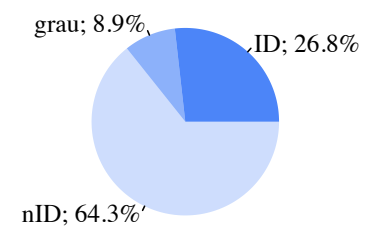

Spontansprache F $(\mathbf{n}=53)$

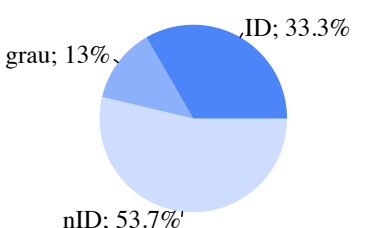

Abbildung 7: Identifizierbarkeit des Sprechers BE1, $I D=$ identifiziert, $n I D=$ nicht identifiziert, grau = identifiziert als "Westschweizer"

Resultate zu BE2 Wie SG1 gehört auch der Sprecher BE2 zu den beiden global am besten lokalisierbaren Sprechern (vgl. Tabellen 5-7): Die Erkennungsraten der standarddeutschen Stimuli sind in der breiten Kategorie signifikant. Beim Französischsprechen wird BE2 in beiden Konditionen von allen Sprechern am leichtesten erkannt. Die weitaus häufigste Antwort für ausnahmslos alle Sprachproben von BE2 ist "Bern". Zusätzlich illustriert wird die starke Erkennbarkeit von BE2 als Berner in Abbildung 8. Erklärungen für diese hohe Identifikationsraten sind für das Standarddeutsche die offenen Vokale, die Aussprache der/r/Laute als alveolare Vibranten sowie die Aussprache von /k/ als Affrikate [kx] in daherkam und prosodische Faktoren, insbesondere die tiefe Artikulationsrate. Für die hohe Erkennbarkeit der französischen Stimuli sind unter anderem ebenfalls prosodische Faktoren sowie die offen gesprochenen Vokale zu nennen. Es fällt auf, dass die französische Spontansprache leichter erkannt wurde, als die Lesesprache. Die standarddeutschen Stimuli jedoch bestätigen die allgemeine Tendenz der leichteren Identifizierbarkeit vorgelesener Sprache. 
Lesesprache $D(n=56)$

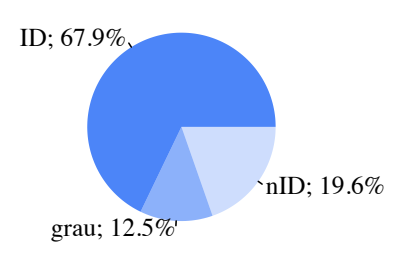

Lesesprache F $(n=54)$

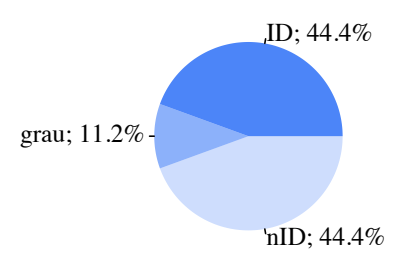

Spontansprache $D(n=55)$

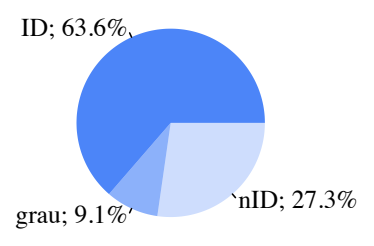

Spontansprache $\mathbf{F}(\mathbf{n}=\mathbf{5 5})$

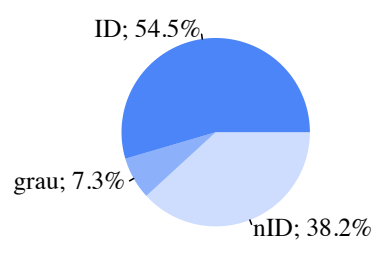

\section{Abbildung 8: Identifizierbarkeit des Sprechers BE2, \\ $I D=$ identifiziert, $n I D=$ nicht identifiziert, grau $=$ identifiziert als "Westschweizer"}

Resultate zu BE3 Die Daten zur Sprecherin BE3 bestätigen die globalen Tendenzen: Sie wird beim Sprechen des Standarddeutschen besser erkannt, als beim Französischsprechen und beim Vorlesen besser als beim freien Sprechen (vgl. Abbildung 9). Die eher schwere Erkennbarkeit des Akzents in den französischsprachigen Stimuli hängt vermutlich damit zusammen, dass BE3 im Französischen einen vergleichsweise schwachen Akzent hat: Das /a/ wird, im Vergleich zu den anderen Bernern, relativ weit vorne gesprochen, die anderen Vokale höher, geschlossener. Die grösste Antwortkategorie bilden für die französischen Stimuli mit einem grossen Anteil die leeren Felder, gefolgt von einem grossen Anteil "Bern". Dabei liegt der relativ hohe Anteil an "Ostschweiz"-Nennungen möglicherweise an den oben beschriebenen Vokalqualitäten. Bei den standarddeutschen Stimuli wird der Modalwert von der Antwort "Bern" gebildet, hier ist die Erkennungsrate hoch - und hängt vermutlich nicht zuletzt am alveolaren /r/-Laut. 
Lesesprache $\mathbf{D}(\mathbf{n}=56)$

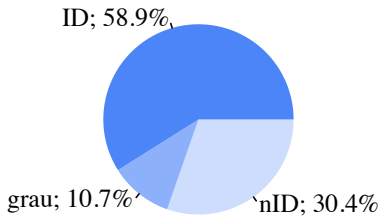

Lesesprache $F(n=54)$

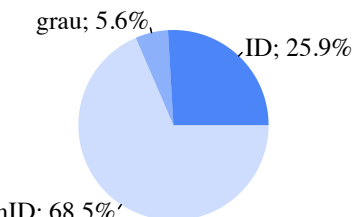

Spontansprache D $(\mathbf{n}=55)$

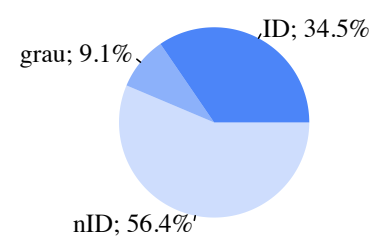

Spontansprache $\mathbf{F}(\mathbf{n}=\mathbf{5 5})$

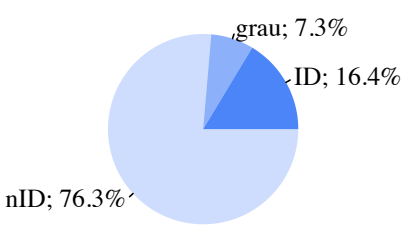

\section{Abbildung 9: Identifizierbarkeit der Sprecherin BE3, \\ $I D=$ identifiziert, $n I D=$ nicht identifiziert, grau $=$ identifiziert als "Westschweizerin"}

Resultate zu BE4 Die Stimuli der Sprecherin BE4 sind in allen Kategorien nur marginal nicht signifikant erkannt worden, insbesondere die spontansprachlichen. Abbildung 10 bestätigt dieses Resultat und die vergleichsweise sehr schmale Grauzone verdeutlicht die geringe Variabilität der Antworten. Bei den französischen Stimuli kehrt sich das Blatt; hier schien die regionale Zuordnung schwierig. Auffällig ist für diese Stimuli die Verdoppelung der Erkennungsrate von der Spontan- zur Lesesprache, für welche vorläufig nur eine pragmatische Erklärung gegeben werden kann: Der spontansprachliche Stimulus ist kürzer und enthält mehr Pausen, also weniger Sprachmaterial und so weniger Indizien zur regionalen Herkunft der Sprecherin. Dies bestätigt insbesondere die allgemeine Tendenz, dass Lesesprache besser erkannt wird als Spontansprache. 


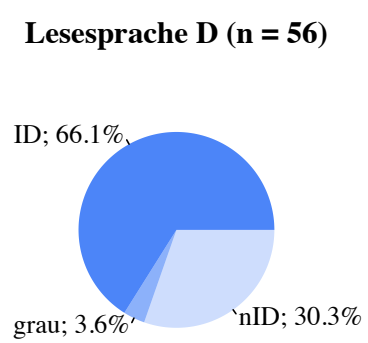

Lesesprache F (n = 54)

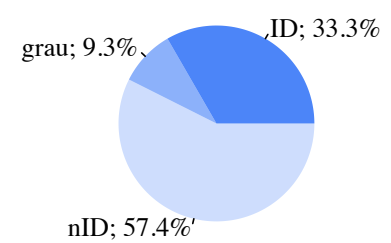

Spontansprache D $(\mathbf{n}=\mathbf{5 4})$

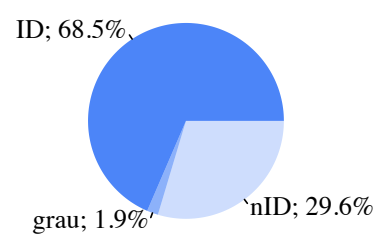

Spontansprache F $(\mathbf{n}=54)$

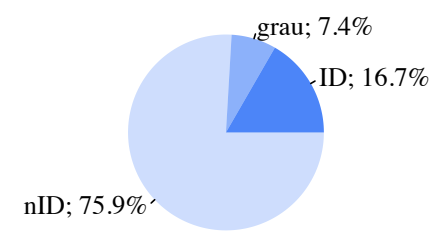

Abbildung 10: Identifizierbarkeit der Sprecherin BE4, $I D=$ identifiziert, $n I D=$ nicht identifiziert, grau $=$ identifiziert als "Westschweizerin"

\subsection{Allgemeine Diskussion}

Die Hypothese, dass ein Standarddeutsch oder Französisch sprechender Deutschschweizer von einem $\mathrm{NaS}$ eines Schweizer Dialekts dialektal lokalisiert werden kann, wurde für die beiden hier untersuchten Dialekte - Stadtbern- und Stadt-St. Gallerdeutsch - und zumindest für die "L2" Standarddeutsch bestätigt. Dies nicht nur aufgrund der Resultate der statistischen Tests, sondern vor allem angesichts der deskriptiven Darstellung und Diskussion der Erkennungsraten zu jedem einzelnen Sprecher, die jeweils vor dem Hintergrund der offenen Fragestellung im Experiment gelesen werden muss. Ein weiteres Argument für die Unterstützung der Hypothese wird aufgrund dieser Diskussion der Daten offensichtlich: Auch dort, wo die Erkennungsraten relativ gering sind, wird die grösste Antwortkategorie fast immer von der richtigen Antwort (oder von leer gelassenen Feldern) gebildet. Falsche Antworten stellen also nie die häufigste (und fast nie die zweithäufigste) Antwort dar - und dies gilt auch für die französischen Stimuli. ${ }^{35}$

Durchschnittlich wurden die standarddeutschen Stimuli von etwa $50 \%$ der Hörerinnen richtig identifiziert, wenn man die oben definierte mittlere Kategorie - Region Bern, Solothurn, Freiburg vs. (Nord-)Ostschweiz - berücksichtigt. Französische Stimuli konnten hier von $30 \%$ der deutschsprachigen Hörer identifiziert werden. Die Unterscheidung zwischen einem globaleren West- oder Ostschweizer Akzent konnte aufgrund der standarddeutschen Stimuli im Durchschnitt von fast $60 \%$ der Hörer, aufgrund der französischen von etwa $40 \%$ der

\footnotetext{
35 Da die vorliegende Studie nur eine kleine Anzahl von acht Sprechern betrachtet, müssen ihre Resultate, was die sprecherbezogene Variation betrifft, als Pilotstudie aufgefasst werden. Diese Resultate können also nicht als endgültig bestätigt betrachtet werden, sondern müssen hypothetisch formuliert werden. Die grosse Anzahl der Probanden jedoch erlaubt für jeden einzelnen Sprecher relativ sichere Resultate.
} 
Hörer getroffen werden. Für französischsprachige Hörerinnen war die Aufgabe offensichtlich schwieriger, mit einer multiple-choice Struktur konnten jedoch auch sie dialektale Akzente erkennen. Leichter fiel frankophonen Hörern die grundsätzliche Unterscheidung der beiden Akzente, da viele dieser Probanden keine mentale Repräsentation davon haben, wie ein Berner im Gegensatz zu einem St. Galler oder Züricher Französisch spricht. Die Resultate sowohl der deutsch- als auch der französischsprachigen Probanden illustrieren die perzeptive Prominenz des lautlichen West/Ost-Gegensatzes in der Schweizer Sprachlandschaft.

Im Vergleich zu den Identifikationsraten von etwa 36\% bei Bauvois (1996: 300f.) sind viele der oben beschriebenen Werte relativ hoch. Dies kann damit erklärt werden, dass die Schweiz auf kleinem Raum eine hohe dialektale Variabilität aufweist. Der Vergleich unserer Erkennungsraten mit Akzent-Perzeptionsstudien wie in Boula de Mareuïl (2008), Guntern (2011) ist schwierig, da die Aufgabenstellung im Experiment jeweils eine andere ist (vgl. 2.1.1). Jedoch stützen die Resultate der vorliegenden Studie diese vorangehenden Resultate zur grundsätzlichen Erkennbarkeit fremdsprachlicher (dialektaler) Akzente.

In lesesprachlichen Stimuli konnten dialektale Akzente im Allgemeinen leichter identifiziert werden, was sowohl an den längeren Texten, als auch an der direkten Vergleichbarkeit des Sprachmaterials zwischen verschiedenen Sprecherinnen liegen kann. Dieses Resultat wird dadurch bestätigt, dass die Sprecherinnen der vorliegenden Untersuchung in Lesesprache auch einen stärkeren Akzent haben (vgl. Kolly 2011).

Die Sprecher, die beim Französischsprechen gut erkannt wurden, sind nicht unbedingt dieselben wie die, welche aufgrund ihrer standarddeutschen Sprachproben eine hohe Erkennungsrate aufweisen. Dies war zu erwarten, da Sprachkompetenzen je Sprache von Sprecher zu Sprecher stark variieren können, und heisst nicht, dass es keinen sprachübergreifenden Berner bzw. St. Galler Akzent gibt. Berner und St. Galler Ausspracheeigenheiten, ihre Prosodie usw. treten aber je nach Sprachkompetenz, affektiven und anderen Variablen in den beiden Sprachen verschieden stark hervor (vgl. Kolly 2011).

Eine Sprecherin, die von allen Hörern (deutsch- und französischsprachigen) leicht kategorisiert werden konnte, ist SG1. Generell wurden aber durch die französischsprachigen Hörerinnen nicht unbedingt die Sprecher am besten lokalisiert, deren dialektaler Akzent von den deutschsprachigen Hörern beim Französischsprechen erkannt wurde. Dies ist vermutlich teilweise in der grundverschiedenen Aufgabenstellung begründet, indem sich die frankophonen Probanden bei der Zuordnung dialektaler Herkunft zwischen nur zwei Optionen entscheiden mussten, die deutschsprachigen aber frei raten sollten und über keine Angaben zur Anzahl der Optionen verfügten. Weiter ist anzunehmen, dass frankophone Hörer bei der Wahrnehmung französischer Stimuli auf andere Merkmale fokussieren als deutschsprachige.

\section{Fazit: Schweizerhochdeutsch ist nicht gleich Schweizerhochdeutsch}

Die vorliegende Studie untersucht, ob dialektal gefärbtes Standarddeutsch und Französisch von Berner und St. Galler Sprechern durch Deutschschweizer Hörer perzeptiv lokalisiert werden kann und ob Romands in dialektal akzentuiertem Französisch verschiedene Akzenttypen wahrnehmen. Generell können die Hypothesen bestätigt werden, wenn sich auch je nach Sprecher, Dialekt, Fremdsprache, Sprechstil und Hörergruppe unterschiedlich hohe Identifikationsraten ergeben.

Als akustische Korrelate dieser perzeptiven Unterscheidbarkeit wurden Vokalqualitäten, die Aussprache bestimmter Konsonanten (insb. der /r/-Laut) sowie prosodische Faktoren (z. B. Sprechtempo) angegeben, welche grösstenteils auch den erwarteten Unterschieden zwischen Produktionen von Dialektsprechern aus Bern und St. Gallen entsprechen (vgl. 3.1, 5.2). Eine direkte Befragung von Hörern nach akustischen Merkmalen, die auf bestimmte dialektale Akzente hinweisen, diskutiert Guntern (2011). 
Auch die Wahl der Hörergruppe ist nicht trivial: Sowohl die linguistische Expertise, als auch die Muttersprache der Hörer ist für die Akzentwahrnehmung von Relevanz. Die vorliegende Untersuchung illustriert erstens die Möglichkeiten und Grenzen der Lokalisierung von Varietäten durch linguistisch untrainierte $\mathrm{NaS}$. Einerseits scheint die Erkennbarkeit von dialektalen Akzenten, die aus so kleinen und einander nahen Gebieten stammen, eine beeindruckende Fähigkeit der menschlichen Wahrnehmung; andererseits zeigt die Fehlerquote auch, dass linguistisch untrainierte NaS bei der Analyse einer Sprachprobe auf lokale Merkmale an Grenzen stossen. Dies hat z. B. Implikationen für die forensische Phonetik und legt nahe, dass für (akustische) Analysen der Sprecherherkunft oder -identität ausgebildete Linguisten gegenüber linguistischen Laien vorzuziehen sind (vgl. Baltisberger/Hubbuch 2010). Zweitens illustriert die vorliegende Untersuchung, dass die Muttersprache einer Hörergruppe für die Lokalisierung fremdsprachlicher Akzente zentral ist. Insbesondere wurde gezeigt, dass Hörer fremdsprachliche Akzente, die von ihnen vertrauten Varietäten stammen, viel differenzierter wahrnehmen und lokalisieren können als Akzente, mit welchen sie wenig Kontakt haben.

Das in der Einleitung abgedruckte Zitat von Friedrich Dürrenmatt antizipiert die Resultate der vorliegenden Studie: Der berndeutsche sowie der St. Galler Akzent konnten im Standarddeutschen wie im Französischen, von Deutschschweizer wie von frankophonen Hörern erkannt werden. Dabei konnten Deutschschweizer Hörer die dialektalen Akzente in standarddeutschen Stimuli viel leichter und differenzierter lokalisieren, als in französischen da Deutschschweizer Hörer mit Französisch sprechenden Deutschschweizern auch weniger vertraut sind, als mit Standarddeutsch sprechenden. "[I]n der französischen Schweiz gibt es viele Deutschschweizer, die so reden, wie ich rede, vor allem viele, die so französisch reden, wie ich französisch rede, rede ich französisch" (Dürrenmatt 1967/1998: 120).

\section{Literatur}

\section{Quelle}

Dürrenmatt, Friedrich (1967/1998): "Persönliches über Sprache". In: ders.: Literatur und Kunst. Essays, Gedichte, Reden. Zürich, Diogenes: 120-124. (= Werkausgabe in siebenunddreissig Bänden 32).

\section{Forschungsliteratur}

Ashby, Michael/Maidment, John (2005): Introducing Phonetic Science. Cambridge: Cambridge University Press. (= Cambridge Introductions to Language and Linguistics).

Atterer, Michaela/Ladd, Robert (2004): "On the Phonetics and Phonology of 'Segmental Anchoring' of F0. Evidence from German". Journal of Phonetics 32/2: 177-197.

Auer, Peter (2001): "Silben- und akzentzählende Sprachen". In: Haspelmath, Martin/König, Ekkehard/Oesterreicher, Wulf (Hrsg.) (2001): Language typology and language universals. An international handbook. Sprachtypologie und sprachliche Universalien. Ein internationales Handbuch. Teilband 2. Berlin/New York, de Gruyter: 1391-1399. (= Handbücher zur Sprach- und Kommunikationswissenschaft 20).

Bachmann, Albert (1908): "[Schweizer-]Sprachen und Mundarten". In: Knapp, Charles/Borel, Maurice (Hrsg.) (1908): Geographisches Lexikon der Schweiz. Bd. 5. Neuenburg, Attinger: $58-76$.

Baltisberger, Eric/Hubbuch, Priska (2010): "LADO with specialized linguists - The development of LINGUA's working method". In: Zwaan, Karin/Verrips, Maaike/Muysken, Pieter (Hrsg.) (2010): Language and origin: The role of language in European asylum procedures. Nijmegen: 9-19.

Bauvois, Cécile (1996): "Parle-moi, et je te dirai peut-être d'où tu es". Revue de Phonétique Appliquée 121: 291-309. 
Bellmann, Günter (1994): Einführung in den Mittelrheinischen Sprachatlas. Tübingen: Niemeyer.

Berthele, Raphael (2010): "Der Laienblick auf sprachliche Varietäten. Metalinguistische Vorstellungswelten in den Köpfen der Deutschschweizerinnen und Deutschschweizer". In: Anders, Christina Ada/Hundt, Markus/Lasch, Alexander (Hrsg.) (2010): "Perceptual dialectology". Neue Wege der Dialektologie. Berlin/New York, de Gruyter: 245-267. (= Linguistik - Impulse und Tendenzen 38).

Bohn, Ocke-Schwen (1998): "Wahrnehmung fremdsprachlicher Laute. Wo ist das Problem?". In: Wegener, Heide (Hrsg.) (1998): Eine zweite Sprache lernen. Empirische Untersuchungen zum Zweitspracherwerb. Tübingen, Narr: 1-20. (= Tübinger Beiträge zur Linguistik. Series A: Language Development 24).

Boula de Mareuïl, Philippe u. a. (2008): "Accents étrangers et régionaux en français. Caractérisation et identification". Traitement Automatique des Langues 49/3: 135-163.

Catford, John C./Pisoni, David B. (1970): "Auditory vs. Articulatory Training in Exotic Sounds". The Modern Language Journal 54/7: 477-482.

Christen, Helen (2005): "'Tour de Suisse' der Deutschschweizer Dialekte". In: Forum Helveticum (Hrsg.) (2005): Dialekt in der (Deutsch)Schweiz - Zwischen lokaler Identität und nationaler Kohäsion. Le dialecte en Suisse (alémanique) - entre identité locale et cohésion nationale. Lenzburg, Forum Helveticum: 21-25. (= Schriftenreihe Forum Helveticum 15).

Christen, Helen (2010): "Was Dialektbezeichnungen und Dialektattribuierungen über alltagsweltliche Konzeptualisierungen sprachlicher Heterogenität verraten". In: Anders, Christina Ada/Hundt, Markus/Lasch, Alexander (Hrsg.) (2010): "Perceptual dialectology". Neue Wege der Dialektologie. Berlin/New York, de Gruyter: 269-290. (= Linguistik Impulse und Tendenzen 38).

Cunningham-Andersson, Una/Engstrand, Olle (1989): "On the Nature of Foreign Accents". Speech Transmission Laboratory Quarterly Progress and Status Report 30/1: 55-58.

Crystal, David (2003): A Dictionary of Linguistics and Phonetics. 5. Auflage. Oxford: Blackwell.

Flege, James E. (1992): "Speech Learning in a Second Language". In: Ferguson, Charles A./Menn, Lise/Stoel-Gammon, Carol (Hrsg.) (1992): Phonological Development. Models, Research, Implications. Maryland, York Press: 565-604.

Flege, James E. (1995): "Second Language Speech Learning. Theory, Findings, and Problems". In: Strange, Winifred (Hrsg.) (1995): Speech Perception and Linguistic Experience. Issues in Cross-Language Research. Timonium, York Press: 233-277.

Fleischer, Jürg/Schmid, Stephan (2006): "Zurich German". Journal of the International Phonetic Association 36/2: 243-253.

Fox, Annette V. (2006): "Evidence from German-Speaking Children". In: Hua, Zhu/Dodd, Barbara (Hrsg.) (2006): Phonological Development and Disorders in Children: A Multilingual Perspective. Cleveland/Buffalo/Tortonto: 56-80.

Fuchs, Gabriela/Werlen, Iwar (1999): Zweisprachigkeit in Biel-Bienne. Untersuchung im Rahmen des Bieler-Bilinguismus-Barometers 1998. Im Auftrag des Forums für Zweisprachigkeit Biel-Bienne. Bericht erstellt auf Basis der Daten des GfSForschungsinstituts Bern. Biel (Stiftung Forum für die Zweisprachigkeit).

Guntern, Manuela (2011): "Erkennen von Dialekten anhand von gesprochenem Schweizerhochdeutsch". Zeitschrift der deutschen Dialektologie 78/2. 155-187.

Haas,Walter (1985): "Sprachgeographie und Variationstheorie". In: Werlen, Iwar (Hrsg.) (1985): Probleme der schweizerischen Dialektologie. 2. Kolloquium der Schweiz. Geisteswissenschaftlichen Gesellschaft. Problèmes de la dialectologie suisse. 2 e Colloque de la Société suisse des sciences humaines. Fribourg, Editions Universitaires Fribourg: 95108. 
Haas, Walter (2000): "Die deutschsprachige Schweiz". In: Bickel, Hans/Schläpfer, Robert (Hrsg.) (2000): Die viersprachige Schweiz. Aarau/Frankfurt am Main/Salzburg, Sauerländer: 57-138. (= Sprachlandschaft 25).

Haas, Walter (2004): "Die Sprachsituation der deutschen Schweiz und das Konzept der Diglossie". In: Christen, Helen (Hrsg.) (2004): Dialekt, Regiolekt und Standardsprache im sozialen und zeitlichen Raum. Beiträge zum 1. Kongress der Internationalen Gesellschaft für Dialektologie des Deutschen, Marburg/Lahn 5.-8. März 2003. Wien, Praesens: 81110.

Häcki Buhofer, Annelies/Burger, Harald (1998): Wie Deutschschweizer Kinder Hochdeutsch lernen. Der ungesteuerte Erwerb des gesprochenen Hochdeutschen durch Deutschschweizer Kinder zwischen sechs und acht Jahren. Stuttgart: Steiner. (= Zeitschrift für Dialektologie und Linguistik; Beihefte 98).

Hirschfeld, Ulla/Trouvain, Jürgen (2007): "Teaching Prosody in German as a Foreign Language". In: ders./Gut, Ulrike (Hrsg.) (2007): Non-Native Prosody. Phonetic Description and Teaching Practice. Berlin/New York, de Gruyter: 171-187.

Historisches Lexikon der Schweiz. Bde. 6, 8. Hrsg. von der Stiftung Historisches Lexikon der Schweiz. Basel: Schwabe.

Holm, Alison/Dodd, Barbara (2006) : "Phonological Development and Disorder of Bilingual Children Acquiring Cantonese and English". In: Hua, Zhu/Dodd, Barbara (eds.) : Phonological Development and Disorders in Children: A Multilingual Perspective. Cleveland/Buffalo/Toronto : 286-325.

Hotzenköcherle, Rudolf (1961): "Zur Raumstruktur des Schweizerdeutschen". Zeitschrift für Mundartforschung 28/3: 207-227.

Hotzenköcherle, Rudolf (1962a): Sprachatlas der deutschen Schweiz. Bd. 1: Lautgeographie: Vokalqualität. Bern/Basel.

Hotzenköcherle, Rudolf (1962b): Einführung in den Sprachatlas der deutschen Schweiz. Bd. A: Zur Methodologie der Kleinraumatlanten. Bern.

Hotzenköcherle, Rudolf (1984): Die Sprachlandschaften der deutschen Schweiz. Hrsg. von Niklaus Bigler und Robert Schläpfer. Aarau usw.: Sauerländer. (= Sprachlandschaft 1).

Hove, Ingrid (2002): Die Aussprache der Standardsprache in der deutschen Schweiz. Tübingen: Niemeyer. (= Phonai; Texte und Untersuchungen zum gesprochenen Deutsch 47).

Hove, Ingrid (2008): "Zur Unterscheidung des Schweizerdeutschen und der (schweizerischen) Standardsprache". In: Christen, Helen/Ziegler, Evelyn (Hrsg.) (2008): Sprechen, Schreiben, Hören - Zur Produktion und Perzeption von Dialekt und Standardsprache zu Beginn des 21. Jahrhunderts. Wien: 63-82.

Jilka, Matthias/Möhler, Gregor (1998): "Intonational Foreign Accent. Speech Technology and Foreign Language Teaching". In: Proceedings of Speech Technology in Language Learning, 25.-27.05.1998, Marholmen, Sweden: 113-116.

Kolde, Gottfried (1981): Sprachkontakte in gemischtsprachigen Städten. Vergleichende Untersuchungen über Voraussetzungen und Formen sprachlicher Interaktion verschiedensprachiger Jugendlicher in den Schweizer Städten Biel/Bienne und Fribourg/Freiburg i. Ue. Wiesbaden: Steiner. (= Zeitschrift für Dialektologie und Linguistik; Beihefte 37).

Kolly, Marie-José (2011): "Weshalb hat man (noch) einen Akzent? Eine Untersuchung im Schnittfeld von Akzent und Einstellung bei Schweizer Dialektsprechern". Linguistik online 50, 6/11: 43-77.

Labov, William (1972): Sociolinguistic Patterns. Oxford.

Labov, William (2006): The Social Stratification of English in New York City. $2^{\text {nd }}$ edition. New York. 
Leather, Jonathan/James, Allan (1996): "Second Language Speech". In: Ritchie, William C./Bhatia, Tej K. (Hrsg.) (1996): Handbook of Second Language Acquisition. San Diego usw.: Academic Press: 269-316.

Leemann, Adrian (2012): Swiss German Intonation Patterns. Amsterdam: Benjamins. (= Studies in Language Variation).

Leemann, Adrian/Siebenhaar, Beat (2008): "Perception of Dialectal Prosody". Proceedings of Interspeech 2008, Brisbane 22.-26.9.2008 : 524-527.

Leemann, Adrian/Dellwo, Volker/Kolly, Marie-José/Schmid, Stephan (2012): "Rhythmic Variability in Swiss German Dialects". Proceedings of Speech Prosody 2012, Shanghai, 22.-25.5.2012.

Leemann, Adrian/Kolly, Marie-José/Sutter, Sibylle/Brander, Dario/Werlen, Iwar/Hasler, Fiona/Eisenblatt, Carina: "Hören wir in Zürich bald Pfnüsu und Tubu statt Pfnüsel und Tubel? Das Fortschreiten der /1/-Vokalisierung in der deutschsprachigen Schweiz". Präsentation an den 7. Tagen der Schweizer Linguistik, Lugano, 13.-14.07.2012.

Lengert, Joachim (1998): Les helvétismes de Suisse romande au XIXe siècle d'après le Journal intime d'Henri-Fr. Amiel. Paris, Klincksieck. (= Matériaux pour l'étude des régionalismes du français 12).

Major, Roy C. (2001): Foreign Accent. The Ontogeny and Phylogeny of Second Language Phonology. Mahwah NJ/London: Erlbaum.

Missaglia, Federica (2007): "Prosodic Training for Adult Italian Learners of German. The Contrastive Prosody Method". In: Trouvain, Jürgen/Gut, Ulrike (Hrsg.) (2007): Non-Native Prosody. Phonetic Description and Teaching Practice. Berlin/New York : 236-258.

Molnár, Heike (2010): "Der Einfluss des Alters auf die Aussprachekompetenz in der L2. Ergebnisse einer Pilotstudie mit DaZ-Lernern". Zeitschrift für interkulturellen Fremdsprachenunterricht 15/1: 1-21. http://zif.spz.tu-darmstadt.de/jg-151/beitrag/Molnar.htm. Stand: 6.8.2010.

Muller, Nathalie (1998): "L'allemand, c'est pas du français!". Enjeux et paradoxes de l'apprentissage de l'allemand. Neuchâtel/Lausanne (Institut de Recherche et de Documentation Pédagogique/Loisirs et Pédagogie).

Purschke, Christoph (2010): "Imitation und Hörerurteil - Kognitive Dialekt-Prototypen am Beispiel des Hessischen". In: Anders, Christina Ada/Hundt, Markus/Lasch, Alexander (Hrsg.) (2010): "Perceptual Dialectology". Neue Wege der Dialektologie. Berlin/New York, de Gruyter: 151-177. (= Linguistik - Impulse und Tendenzen 38).

R Development Core Team (2010): R. A Language and Environment for Statistical Computing. Wien: $\mathrm{R}$ Foundation for Statistical Computing. http://www.R-project.org. Stand: 1.6.2010.

Schläpfer, Robert (2000): "Einleitung". In: Bickel, Hans/Schläpfer, Robert (Hrsg.) (2000): Die viersprachige Schweiz. Aarau/Frankfurt am Main/Salzburg, Sauerländer: 11-15. (= Sprachlandschaft 25).

Schmid, Stephan (2009): La prononciation du français par des élèves d'un lycée zurichois. In: Hans-Rudolf Nüesch (Hrsg.) (2009): Galloromanica et Romanica. Mélanges de linguistique offerts à Jakob Wüest. Tübingen, Francke: 253-268.

Schmidt, Lothar (2003): "Französich". Phonetik international: 1-14.

Siebenhaar, Beat (1994): "Regionale Varianten des Schweizerhochdeutschen. Zur Aussprache des Schweizerhochdeutschen in Bern, Zürich und St. Gallen". Zeitschrift für Dialektologie und Linguistik 61: 31-65.

Sprachatlas der deutschen Schweiz (SDS) (1962-2003). Bern (I-VI), Basel: Francke (VIIVIII).

Strik, Helmer/Cucchiarini, Catia/Binnenpoorte, Diana (2000): "L2 Pronunciation Quality in Read and Spontaneous Speech". In: Proceedings of the 6th International Conference on Spoken Language Processing, Beijing, China, 16-20 October 2000 : 582-585. 
The International Phonetic Association (1999/2003): Handbook of the International Phonetic Association. A Guide to the Use of the International Phonetic Alphabet. Cambridge: Cambridge University Press.

Thibault, André (2004): Dictionnaire suisse romand. Particularités lexicales du français contemporain. Nouv. éd, rev. et augmentée, prép. par Pierre Knecht. Carouge-Genève, Zoé.

Thompson, Irene (1991): "Foreign Accents Revisited. The English Pronunciation of Russian Immigrants". Language Learning 41/2: 177-204.

Werlen, Iwar (Hrsg.) (2000): Der zweisprachige Kanton Bern. Bern/Stuttgart/Wien: Haupt.

Werlen, Iwar (1980). "R im Schweizerdeutschen". Zeitschrift für Dialektologie und Linguistik 47: 52-76. 